\title{
Pay What Your Dad Paid: Commitment and Price Rigidity in the Market for Life Insurance*
}

\author{
Radoslaw Paluszynski ${ }^{\dagger} \quad$ Pei Cheng $\mathrm{Yu}^{\ddagger}$
}

This version:

February 28, 2019

\begin{abstract}
Life insurance premiums display significant rigidity in the data, on average adjusting once every 3 years by more than $10 \%$. This contrasts with the underlying marginal cost which exhibits considerable volatility due to the movements in interest and mortality rates. We build and calibrate a model where policyholders are held-up by long-term insurance contracts, resulting in a time inconsistency problem for the firms. The optimal contract takes the form of a simple cutoff rule: premiums are rigid for cost realizations smaller than the threshold, while adjustments must be large and are only possible when cost realizations exceed it.
\end{abstract}

Keywords: Life insurance, Time inconsistency, Hold-up problem, Commitment, Flexibility

JEL Classification Numbers: G22, L11, L14

${ }^{*}$ We are indebted to Motohiro Yogo for his encouragement and advice. We thank Martin Byford, Daniel Gottlieb, Igal Hendel, Kyle Herkenhoff, Anton Kolotilin, Edward Kung, Hongyi Li, Hodaka Morita, David Rahman, Breanne Richins, Jim Schmitz and Kei-Mu Yi for many helpful comments, as well as Witold Paluszyński for his support with automating the collection of data. We also received helpful feedback from participants of the 2019 NBER Insurance workshop, 2018 EARIE annual conference, 2018 European Econometric Society summer meeting, 2018 Australasian Economic Theory workshop, 2016 Texas Theory Camp, 2014 China Econometric Society meeting, 2014 Asia Econometric Society meeting, 2014 North American Econometric Society summer meeting, 2014 Midwest Economic Theory meeting; as well as seminar participants at University of Technology Sydney and Warsaw School of Economics.

${ }^{\dagger}$ University of Houston (e-mail: rpaluszynski@uh.edu)

${ }^{\ddagger}$ University of New South Wales (e-mail: pei-cheng.yu@unsw.edu.au) 


\section{Introduction}

Several studies have documented and modeled the stickiness of consumer goods prices, while price rigidity of long-term financial services remains less examined. This is important because such products constitute a non-negligible fraction of household spending. For example, the share of married household expenditures on personal insurance and pensions in 2016 was $11.1 \%$, compared to $11.8 \%$ on food or $17.5 \%$ on transportation. ${ }^{1}$ This paper documents the high degree of price rigidity for a specific long-term financial contract, life insurance. We propose a novel theory of endogenous price rigidity based on the trade-off between commitment and flexibility for the life insurance company, which is generated by the consumer hold-up problem in long-term contracting.

We show that life insurance premiums are characterized by long periods of rigidity with occasionally sizable adjustments. This is intriguing because the underlying marginal cost of life insurance is volatile over time, with a monthly coefficient of variation of $6.3 \%$ and the average absolute month-to-month change of $1.4 \%$ of the mean. In the data though, the overall probability of a monthly premium change amounts to just $2.6 \% .^{2}$ This implies an average premium duration of roughly 39 months, placing life insurance on the far-right tail of the price change frequency distribution documented by Bils and Klenow (2004). Figure 1 presents an illustrative plot of premiums over time for the most significant and longestobserved companies in our sample. Remarkably, some products have maintained a constant premium for over 20 years, rendering it possible that a son could pay the same amount for life insurance as his father used to, as the title of this paper goes. More generally, our empirical findings indicate that life insurance companies tend to maintain stable profiles of premiums with respect to age. This means that over the life cycle, young policyholders will likely pay the same amount as what older cohorts used to.

To explain the empirical findings, we construct an OLG model where the firm faces a commitment versus flexibility trade-off, which stems from the consumer hold-up problem. Consumers live for three periods and buy one of two types of policies from monopolistically competitive firms, renewable or non-renewable. They incur a transaction cost before purchasing, which represents the monetary expenses and opportunity cost of research and medical examination. They may also experience adverse health shocks in the second period, which could lead to significant premium hikes if they searched for a new policy. In the second period, non-renewable policyholders potentially face all these costs, while renewable policyholders are guaranteed coverage at no additional expense. Therefore, renewable pol-

\footnotetext{
${ }^{1}$ Bureau of Labor Statistics, Consumer Expenditures 2016.

${ }^{2}$ Addressing a common concern, we control for the phenomenon of firms launching new products whenever they attempt to change premiums.
} 


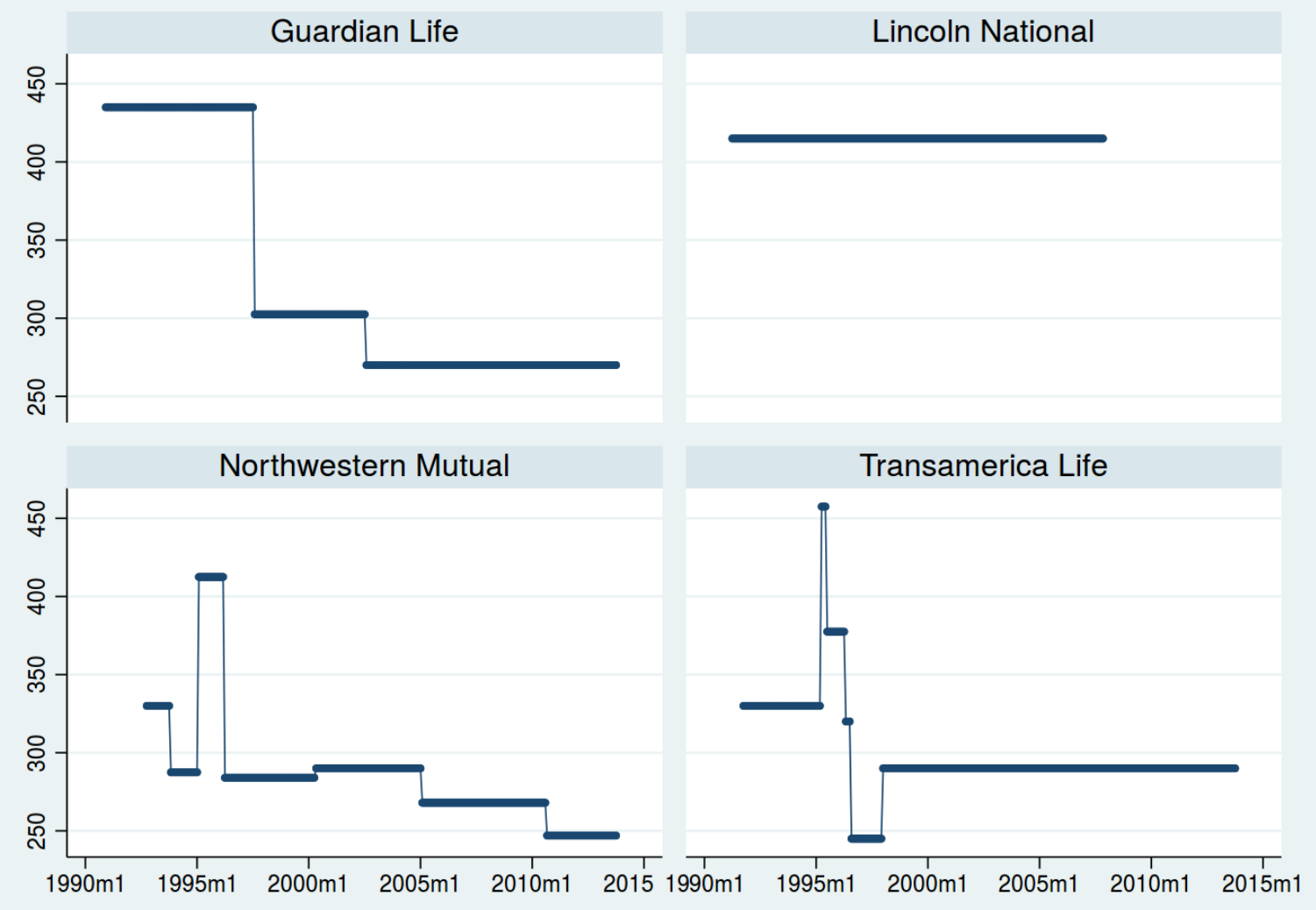

Note: For illustration, we plot here the companies with: i. a share in the California life insurance market of at least 1\% according to California Department of Insurance (2004), and ii. a continuous presence in our sample for at least 180 months (15 years). The total share in the life insurance market for these four companies was $9.3 \%$ in 2003.

Source: Compulife Software, 1990-2013.

Figure 1: ART premiums over time for selected companies

icyholders are locked into a long-term relationship with the company, limiting their future options. This creates an incentive for the firm to raise renewal prices, which also lowers the consumers' ex ante willingness to sign. In essence, the firm is time-inconsistent and values commitment. The firm also faces stochastic cost shocks in the second period, so it values flexibility. Policyholders do not observe the shocks, so they are unsure if premium hikes are due to being held-up or due to changes in the cost. Consequently, the firm needs to design premiums that leave consumers with no doubt that price changes are caused by cost shocks.

To balance the need for commitment and the desire for flexibility, the firm optimally commits to a constant premium for small cost variations, while premium adjustments are large and only possible when cost shocks are substantial. The renewal demand of lockedin policyholders is inelastic to small price increases. This implies that small variations in 
prices are not credible because the firm could increase premiums slightly without losing any consumers. Since the premium adjustment is minor for small cost shocks, the firm commits to a single low premium for all shocks sufficiently small to gain credibility. For premium adjustments to be credible, increases from the low premium need to be significant to induce enough reduction in demand. This way, premium changes can only be attributed to large cost shocks and not ascribed to opportunistic behavior.

We show that the optimal premium as a function of cost has a simple cutoff rule: premiums are low and rigid for marginal costs below an endogenously determined threshold, while above this threshold premiums are high and initially rigid before full flexibility is possible. ${ }^{3}$ Our model explains why level-term insurance policies have a non-guaranteed premium schedule that affords them the room to be flexible, while the finalized premiums rarely deviate from it. We show that the optimal premium is self-enforcing through a reputation mechanism where future consumers cease to sign with the firm if deviation occurs.

Having established the general properties of an optimal premium, we proceed to solve the model numerically and calibrate it to match the quantitative features of ten-year renewable insurance. The model generates realistic premium amounts and predicts a jump in the premium of $12 \%$ when the cost shock switches between the low and high regions, in line with what we observe on average in the data. Interestingly, we find that in the numerical exercise the company does not find it optimal to allow for the premium to be fully responsive to cost, even for the largest cost shocks. Instead, the company switches between a low rigid premium and a high rigid premium. We then use the quantitative model to perform several comparative statics exercises, highlighting the subtle differences between the consumer's hold-up problem and the traditional monopoly power.

We finally test the model predictions directly on our dataset of insurance premiums. First, we find that between the 1990s and the 2000s, a period of time when the consumer's hold-up problem was likely weakened due to falling transaction costs and less adverse health shocks, the frequency of premium changes increased and the average size of such adjustments fell, bringing the pricing patterns of life insurance companies closer to those in typical consumer goods markets. Second, we show that as the level-term of a renewable policy increases, which weakens the hold-up problem due to a higher probability of policy termination before the renewal date, premiums are also more likely to be adjusted and exhibit smaller jumps. Third, we demonstrate that life insurance companies tend to respond to cost shocks predominantly on the extensive margin, by increasing the hazard of a premium change, while no apparent effect is detected on the intensive margin, by varying the size of a premium change. This observation is in line with our model where pricing is based on a threshold rule. Fourth, we

\footnotetext{
${ }^{3}$ The upper rigidity result is similar to Melumad and Shibano (1991) or Alonso and Matouschek (2008).
} 
contrast life insurance premiums with prices of annuities, a related product whose buyers are not held-up by the firm. We find that these prices adjust very frequently and by small margins, providing a validation for our theory. Finally, we test several common alternative models of price rigidity, such as time- and state-dependent sticky price models, and show that their predictions are not consistent with the facts about life insurance premiums.

To summarize, our paper makes three contributions. On the empirical side, we provide evidence for the frequency and size of price changes in the life insurance market, and propose an explanation for this phenomenon. On the theoretical side, we build a model where the optimal incentive compatible contract necessarily features price rigidity and a discrete jump. Finally, we calibrate our commitment versus flexibility model to the life insurance market and show that the predicted premium rigidity and jumps are quantitatively significant.

Our paper provides support for a crucial assumption in the literature on life insurance contracts. In a seminal paper, Hendel and Lizzeri (2003) examine cross-sectional data on life insurance premiums to show that when policyholders lack commitment and face health reclassification risk, the optimal insurance contracts exhibit front-loading. However, the analysis of Hendel and Lizzeri (2003) relies on the assumption that insurers keep their promises in that premiums for older cohorts are the future premiums. In essence, they use the data from a single point in time (July 1997), making an implicit yet crucial assumption that companies never deviate from the current non-guaranteed premiums. ${ }^{4}$ Several papers have since extended this framework while retaining this implicit assumption. Daily et al. (2008) analyzed the effect of secondary markets on front-loading. Fang and Kung (2018) considered the consequences of introducing health-contingent cash surrender values, which work in a similar fashion to secondary markets. The front-loading of contracts motivated Fang and Kung (2012) to ask whether lapsation is driven by income, health or bequest shocks. Fang and $\mathrm{Wu}$ (2019) examined a setting where policyholders underestimate the probability of lapsing due to the loss of bequest motives, and showed that secondary markets could improve welfare. Alternatively, Gottlieb and Smetters (2016) show how front-loaded contracts exploit policyholders who underestimate the probability of an adverse income shock. ${ }^{5}$

This paper also contributes to the empirical literature on life insurance. Koijen and Yogo (2015) show that life insurers have recently been posting highly negative markups which can be explained by financial frictions around the 2008 crisis. Our paper provides an alternative theory for why many of these companies were reluctant to increase premiums in the presence of large marginal cost. Ge (2019) shows that firms often adjust life insurance premiums in

\footnotetext{
${ }^{4}$ The authors support this by citing a July 1993 issue of Consumer Reports.

${ }^{5}$ Recent developments in the literature has focused on departures from the fully rational model, which help explain many empirical facts. For example, Gottlieb (2018) finds that prospect theory helps explain several puzzling behavior in the life insurance market.
} 
response to shocks to their divisions in other markets. Her story suggests that on their own, life insurance premiums may be even more rigid than the analysis in our paper indicates.

Our model is also related to the literature on optimal delegation and self-control. These papers analyze a principal-agent setting with no transfers in which a biased agent is better informed. The principal has full commitment and chooses a set of actions that the agent can take. This is similar to our paper since the firm commits to a subset of renewal premia that it chooses from ex-post. Main references for the literature on delegation include Holmstrom (1984), Melumad and Shibano (1991), Alonso and Matouschek (2008) and Amador and Bagwell (2013). Similar frameworks have been applied to the commitment versus flexibility trade-off for time-inconsistent agents (Amador et al., 2006). Our paper differs from the literature in three distinct ways. First, in our model, the time inconsistency of the firm is endogenous. The firm is able to decrease or even eliminate its intertemporal conflict,

but we show quantitatively that it does not under empirically relevant parameters. Second, the optimal premium will always contain a discontinuous jump if the firm has discretion in adjusting the premiums in the future. This is in contrast to previous literature which has found conditions for interval delegation to be optimal. Third, our paper provides empirical support for the trade-off between commitment and flexibility, which has not been quantified or tested in this literature.

The remainder of the paper is structured as follows. Section 2 describes the construction of our dataset and summarizes the main findings about price dynamics in the life insurance market. Section 3 develops the theoretical model. In Section 4 we present the main qualitative predictions of the model, calibrate it and perform a numerical analysis of the solution. Section 5 empirically tests the main predictions of the model and addresses common alternative theories, and Section 6 concludes. The Appendices contain the proofs to theorems and lemmas presented in the main text, a description of the numerical algorithm, and some more nuanced discussions of our data.

\section{Life Insurance Prices}

In this section we describe the empirical setting of our paper. We start by explaining how renewable level-term insurance works, introduce the dataset of historical premiums, and discuss our findings on premium rigidity. We then show that marginal cost of life insurance is volatile over time, which presents a puzzle in light of the rigid premiums. We conclude by explaining how these findings motivate the construction of our model in Section 3. 


\subsection{Contract Description}

We focus our attention on the renewable level-term form of insurance. These contracts require a down payment of yearly premium at the moment of signing and stay in force for a pre-defined period, typically between one and twenty years. After the term expires, customers face a premium schedule that increases with age and are allowed to renew the policy without undergoing a medical reclassification. Table 1 presents the structure of an one-year level-term insurance policy, commonly referred to as the Annual Renewable Term (ART), for the first 10 policy years. In order to help the consumers undertake this longterm commitment, the contract stipulates a projected path of premiums based on the rates currently offered to older individuals in the same health category (the "Non-Guaranteed Current" column). This schedule is not binding though, and the company may change it at any point in the future. From a legal standpoint, the insurer only commits to an upper bound on future premiums (the "Guaranteed Maximum" column), which vastly exceeds the amounts that can be expected in a market equilibrium.

A natural question to ask is: how often do life insurance companies change their premium schedules? The next section answers this question by constructing a dataset of historical premiums to verify that companies indeed tend to honor these non-binding commitments. This in turn supports the assumption in Hendel and Lizzeri (2003) that consumers know the renewal contract upon signing.

Table 1: Structure of an Annual Renewable Term (ART) contract

\begin{tabular}{rrr}
\hline Age & $\begin{array}{r}\text { Guaranteed Maximum } \\
\text { Contract Premium }\end{array}$ & $\begin{array}{r}\text { Non-Guaranteed Current } \\
\text { Contract Premium }\end{array}$ \\
30 & 270.00 & $270.00^{*}$ \\
31 & 550.00 & $280.00^{*}$ \\
32 & 565.00 & $285.00^{*}$ \\
33 & 582.50 & $297.50^{*}$ \\
34 & 605.00 & $302.50^{*}$ \\
35 & 632.50 & $325.00^{*}$ \\
36 & 670.00 & $330.00^{*}$ \\
37 & 712.50 & $332.50^{*}$ \\
38 & 757.50 & $350.00^{*}$ \\
39 & 820.00 & $360.00^{*}$ \\
\hline
\end{tabular}

Note: Sample contract offered by the Guardian Life Insurance Company of America (first ten years). Face value $=\$ 250,000$. The asterisk in the last column is a standard feature and indicates that premiums are non-guaranteed. Source: Compulife Software, December 2004. 
We measure the insurance companies' adherence to these non-binding promises by collecting premiums data for a fixed-age customer, as described in the next section. ${ }^{6}$ This approach is reasonable because we generally observe in the data that companies tend to adjust entire age schedules, rather than individual premiums separately. So while there is some measurement error involved, in Appendix A we show that it is likely to be small. Moving on to the next section, we thus assume that the pricing patterns for a fixed profile are a good approximation for how credible these non-binding projections are.

\subsection{Data Construction}

We construct a sample of life insurance premiums from Compulife Software, a commercial quotation system used by insurance agents. The programs are released monthly, spanning the period from May 1990 until October 2013. For each of the 282 months collected, we recover the premiums for 1-, 5-, 10- and 20-year renewable term policies offered by different companies. ${ }^{7}$ Even though Compulife is not a complete dataset, it covers most of the major life insurers with an A.M. Best rating of at least A-. As the default customer characteristics we use a 30-year-old male, non-smoker, with the "regular" health category, purchasing a policy with face value of $\$ 250,000$, in California. The choice of this particular state is by Compulife's recommendation, due to a relatively large population and wide representation of insurance companies. The obtained sample consists of 55,829 observations on annual premiums for 578 different policies offered by 234 insurance companies. ${ }^{8}$ Naturally, over the course of 23 years these firms tend to disappear or merge, as well as discontinue their old products and launch new ones. Some new policies may actually be launched as a deliberate strategy to adjust premiums. We keep track of all such transformations whenever possible, merging the premium series of products with seemingly identical characteristics. We also eliminate the seemingly duplicate products offered by the same company, always keeping the one with lower price. In the resulting sample, on average we observe each product for around 96 months (with a median of 84). The fact that different policies have variable duration of lifespan in our data may be related to Compulife's own policy for selecting the companies to include in their listings.

\footnotetext{
${ }^{6}$ As explained in Section 2.2, we undertake this approach for practical reasons. Even though finding the full schedules of premium renewals with respect to age for each company in each month is theoretically possible, it would be prohibitively costly as we would not be able to automate the data collection.

${ }^{7}$ To extract the data from Compulife programs, we obtain screenshots with premium listings and apply a dedicated optical character recognition (OCR) script to convert them into numeric data. This approach is particularly useful for the pre-1997 programs which can only be run under MS-DOS operating system.

${ }^{8}$ Because of occasional incompleteness of Compulife data (especially in the 1990s), we impute the prices whenever a discontinuity appears for up to at most 12 months. The imputed data constitutes roughly $1 \%$ of the final sample size. We also drop all the products that are observed for less than 12 continuous months.
} 


\subsection{Historical Premiums}

Table 2 provides a statistical description of price rigidity in our dataset. Among 578 distinct insurance products that appear for at least 12 continuous months in the sample, only 369 change their premium ever. The probability of a change in any month is $2.59 \%$, resulting in an average premium duration of roughly 39 months. Table 2 includes a vast number of companies that do not adjust prices even once. This may be a deliberate business strategy, but it may also result from other, non-market-oriented factors. ${ }^{9}$ Hence, we also calculate the statistics for the subsample of insurance policies that display at least one premium change. Among those products the probability of a monthly price adjustment increases slightly, but still remains low at 3.4\%, resulting in an average duration of almost 28 months. It should also be noted that products whose price adjusts in the dataset, also tend to stay around for a longer time (114 months as opposed to an unconditional average of 96 months). This observation suggests that certain insurance policies tend to be discontinued (and replaced by new ones) rather than to deviate from the previously promised premium schedule.

We observe a total of 1432 instances of premium adjustment, consisting of 580 hikes and 852 drops. Whenever they occur, premium changes tend to be of large magnitude, over $10 \%$ on average, although we also observe many small changes which yields a median change of around $8 \%$. Overall, the size distribution of price changes in the life insurance market looks similar to the broad class of consumer products, as documented by Klenow and Kryvtsov (2008). ${ }^{10}$ In particular, the distribution is leptokurtic (kurtosis is around 5.5) meaning that more mass is concentrated around zero and in the tails relative to a normal distribution (kurtosis $=3$ ). However, it is unclear how this distribution compares to other financial services, because very little evidence is available in the literature.

In order to visualize these findings, Figures 2(a) and 2(b) take a closer look at the distribution of premium durations and adjustment sizes. The former depicts a standard view of a distribution of durations with significant positive skewness and a long right tail reaching up to 20 years! Each bin in the histogram represents 6 months, which means that roughly $35 \%$ of premiums spell last up to 12 months, while the majority last longer than a year. The second chart presents the distribution of relative sizes of price adjustments, together with a fitted normal density plot. As it is clear from the summary statistics in

\footnotetext{
${ }^{9}$ For instance, an insurance company that has no interest in selling certain types of policies may still offer them as a reference for tax authority.

${ }^{10}$ Naturally, life insurance is different from typical CPI basket goods in that it provides a nominal face value rather than a real consumption value. Hence, inflation provides at best a second-order pressure on premium changes (via the company's strategic behavior), as we show in more detail in Appendix B. Hence, all else constant it should not be surprising that life insurance premiums are rigid even in the presence of positive inflation. On the other hand, as we demonstrate in Section 2.4, life insurance products exhibit volatile cost shocks which is not necessarily the case for many goods included in the CPI basket.
} 
Table 2: Price rigidity in the sample

Total number of observations

55,829

Total number of insurance products observed

Total number of products that change price

369

\section{Whole sample:}

Probability of a monthly price change (in \%)

Median probability of a price change (in \%)

Average number of observations per product

96.59

\section{Excluding the companies that never adjust:}

Probability of a monthly price change (in \%)

Median probability of a price change (in \%)

Average number of observations per product

113.82

\section{Total number of premium adjustments:}

All premium changes

Premium hikes only

Premium drops only

852

Distribution of adjustment size (in \%):

All premium changes

Average Median Kurtosis

Premium hikes only

10.74

7.94

5.56

Premium drops only

10.58

7.41

5.99

10.85

8.49

5.14

Table 2, premium drops occur more often and are of slightly larger magnitude. The size of adjustments reach as much as $50 \%$ in both directions. The distribution also exhibits fatter tails and more concentration around zero than the normal one.

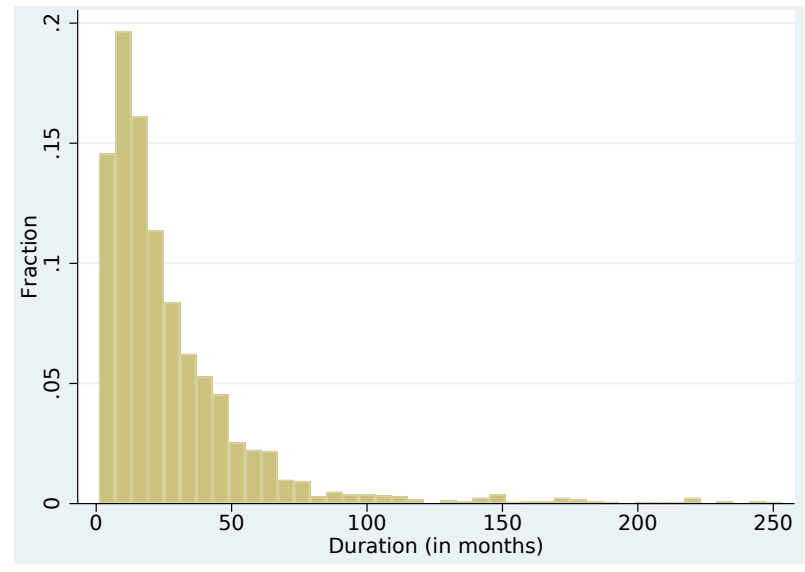

(a) Histogram of premium durations

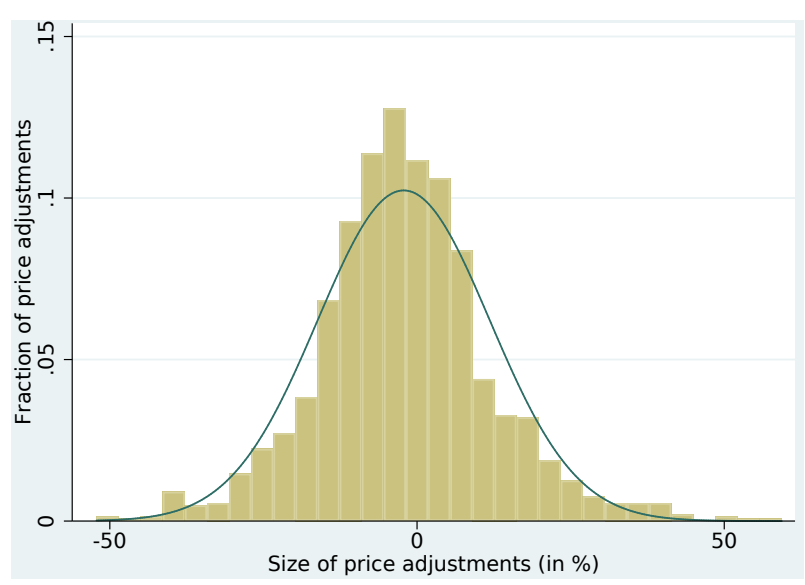

(b) Histogram of adjustment sizes

Figure 2: Distribution of premium durations and adjustment sizes 
In a final piece of data analysis, we explore the distribution in insurance premiums in our sample by examining the relative price dispersion. Figure 3 sketches a histogram of all premiums relative to the current monthly average (for a given renewable term), which is normalized to 100. The striking feature of the graph is the long right tail which implies that some life insurance policies are offered at a premium 2.5 times as high as the average in that category, at a given point in time. More generally, even though life insurance may seem to be a rather homogeneous financial product, we observe a significant dispersion across policies. This may be attributed to varying terms and conditions of different policies (we aggregate all products in the category "renewable level-term" by term duration), as well as the imperfectly competitive environment in which life insurance companies operate. These imperfections may include search frictions (Hortacsu and Syverson, 2004), information frictions or product differentiation (e.g. with respect to company reputation or brand loyalty).

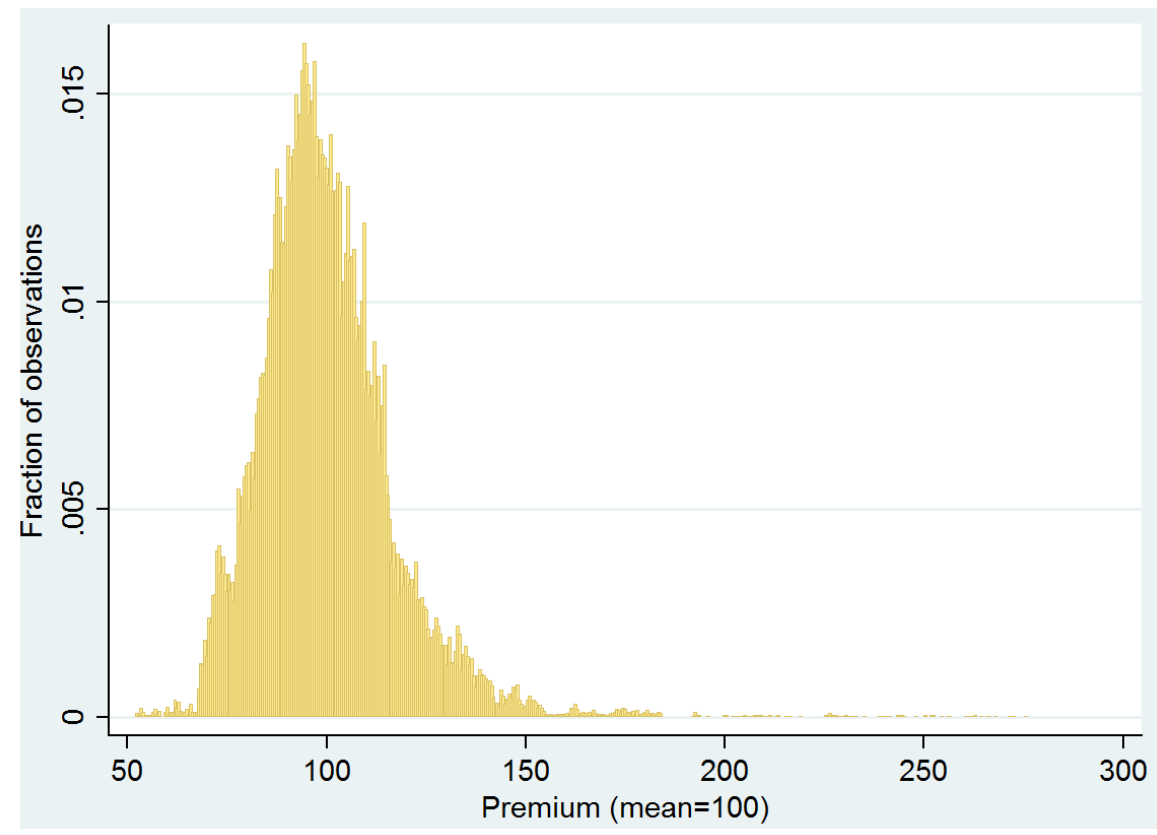

Figure 3: Distribution of insurance premiums, relative to the cross-sectional average

\subsection{Marginal Cost Estimation}

The rigidity of premiums over time may not appear puzzling unless we have an understanding of the dynamics of the underlying marginal cost of life insurance. In this section we show how this cost can be constructed using publicly available data, specifically the interest and mortality rates. We approximate marginal cost by calculating the actuarially fair value of a renewable level-term policy. A precise description of the method we use is provided in 
Appendix C. Intuitively, actuarially fair value can be thought of as a price that satisfies a zero-profit condition faced by the insurance company. Figure 4 presents a stylized illustration of an insurer's cash flow structure. A $k$-year renewable level-term insurance policy is effective from the moment the first premium is paid, period $t$, and stays in force for as long as the customer keeps renewing it. Premiums are increasing with age every $k$ years and the benefit is paid out by the company at the moment of death of the insured, denoted $t+n$. In order to break-even, the firm must charge a stream of premiums $\left\{P_{t}\right\}$ such that the present expected value of cash flows between the company and the policyholder are equalized, i.e. $\sum_{s=0}^{N} \frac{E_{t}\left[P_{t+s}\right]}{R_{t}^{s}}=\sum_{s=0}^{N} \frac{E_{t}\left[B_{t+s}\right]}{R_{t}^{s}}$.

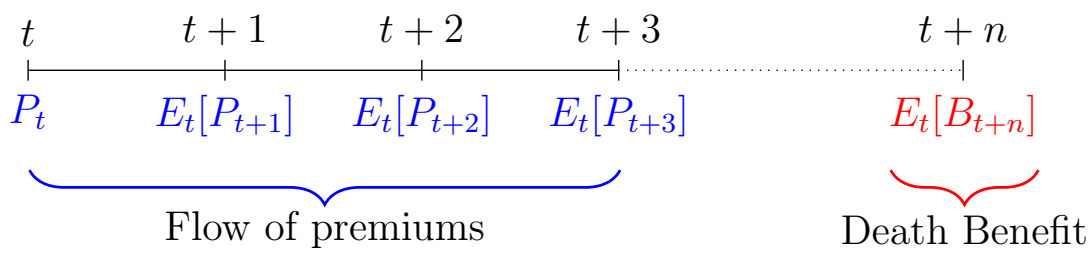

Figure 4: Stylized illustration of a life insurer's expected cash flows

Figure 5 plots the evolution of the actuarially fair value for an ART policy, from May 1990 until October 2013. ${ }^{11}$ It ranges from as low as $\$ 196$ (in November 1994) up to $\$ 291$ (in December 2008), with mean of $\$ 216$ and a standard deviation of \$13.6. Notice the considerable fluctuations over time that result from high frequency movements in the interest rate and low frequency movements in mortality rates. A slight upward trend can be observed throughout the sample, which is a consequence of two opposing long-term empirical patterns - a decline in interest rates, and a decline in mortality of the insured. In particular, the actuarially fair value exhibits a sharp spike in December 2008 when interest rates plunged to record low, and a similarly high level in the post-2011 period of the zero lower bound.

\subsection{From Data to Model}

We have documented that life insurance premiums tend to be rigid over time and exhibit infrequent large adjustments, while the marginal cost of issuing policies is volatile. Two important aspects of the data need to be emphasized in order to motivate the construction of our model in the next section.

First, while our data tracks the premiums over time for a fixed-age consumer, its rigidity also implies that firms tend to maintain their entire age profiles of premiums stable over

\footnotetext{
${ }^{11}$ We assume here that the customer does not voluntarily lapse before turning 60 years of age.
} 


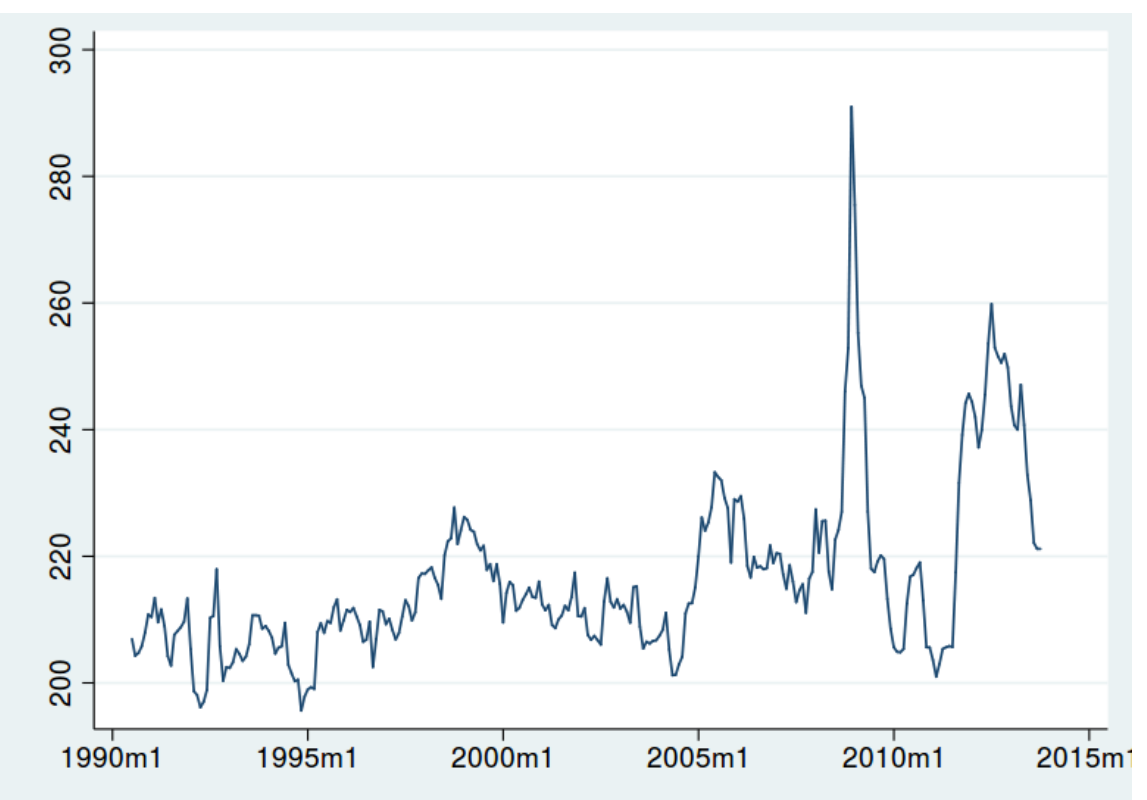

Figure 5: Actuarially fair value for an Annual Renewable Term policy over time time. This is because life insurance companies generally tend to adjust entire premium profiles, rather than individual premiums for different ages (in Appendix A we discuss the potential scope for measurement error involved in this assumption). For example, denote the life insurance premium as function $P(t, a, x)$, where $t$ is time, $a$ is age, and $x$ is the initial characteristics of a customer which we take as given. If premium $P(t, 31, x)$ is constant for all $t$, then a customer renewing at age 31 in 2011 pays the same premium as he anticipated at age 30 in 2010. In other words, the company keeps its non-binding promises towards the renewing customers. Our model, which follows a generation of aging policyholders who face renewal decisions in the future, will offer an explanation to why an insurance company has incentive to honor its non-binding commitment towards them.

A natural concern may be if the renewing customers always pay the same premium as the incoming ones. Following the terminology of Hendel and Lizzeri (2003) we can distinguish Aggregate ARTs, where premiums indeed vary in age but not across cohorts, as well as Select and Ultimate ARTs where customers of the same age may pay different premiums depending on when they had their last medical exam. In the latter policy type, older customers who do not get a new medical checkup will pay a higher premium than newcomers of the same age. While we do not have an easy way to extract the $\mathrm{S} \& \mathrm{U}$ renewal premiums from our dataset, it can be argued that the holders of such policies assign positive probability to getting a medical exam in the future and qualifying for the lowest rate (by revealed preference). Hence, the renewing customers at least have an option to pay the same premiums as the newcomers, and the company must take this into account in the design of its pricing strategies. 
A second remark concerns the potential effects of inflation on our price dynamics. The premium amounts we present here are nominal, while our model in the following section is formulated in real terms. As we explain in Appendix B, this is without loss of generality as long as inflation is constant (which is approximately true for the analyzed period of time in the United States). This is because while inflation erodes the value of premiums over time, it does so to the expected death benefit as well. Thus, nominally rigid premiums for a policy with fixed nominal face value translate into rigid real premiums per dollar of real face value.

\section{The Model}

In this section, we present a dynamic pricing model of renewable life insurance. After setting up the model, we characterize consumer demand, define incentive compatible premiums and the firm's optimization problem.

\subsection{The Setup}

\subsubsection{Consumers and Preferences}

We consider an economy consisting of overlapping generations of three-period-lived consumers. ${ }^{12}$ The economy operates in discrete time, $t=0,1,2, \ldots$ At each date $t$, there is a continuum of consumers with demand for insurance, where a unit of them are young and the rest are old. We refer to the young born in $t$ as consumers of generation $t$. For each generation $t$, the young decide whether to purchase insurance at $t$ and whether to renew, lapse or search for a new policy when old at $t+1$. The life insurance market does not exist for generation $t$ consumers at $t+2$, because they are dead in $t+3$ and beyond.

We assume that all young consumers are of the same health category, and face a population-average mortality risk $m_{y} \in(0,1)$. We denote the population-average mortality risk of the old as $m_{o} \in(0,1)$.

Consumers are heterogeneous in their private reservation price for owning a policy when old, which is denoted as $r_{o}$. The reservation price is assumed to be the same for all consumers when young: $r_{y}=r{ }^{13}$ Private valuation $r_{o}$ is drawn from a continuous and differentiable distribution $h\left(r_{o}\right)$ and c.d.f. $H\left(r_{o}\right)$ with support $[\underline{R}, \bar{R}]$. We assume $\bar{R}>\underline{R} \geq 0$ and $\bar{R}$ is sufficiently large so there is positive demand for insurance coverage when old even if the firm is facing large cost shocks. We also assume that the hazard rate is non-decreasing for $H$.

\footnotetext{
${ }^{12}$ The overlapping generations structure helps us endogenize the cost of deviating from the optimal premium function, which is explored in Appendix F.

${ }^{13}$ The main results of the paper are unchanged if $r_{y}$ is heterogeneous.
} 
Only the distribution of valuations is common knowledge, so life insurance companies are unable to write individual-specific contracts. Consumers also have discount factor $\delta \in(0,1)$. We normalize the value of not owning life insurance to $0 .{ }^{14}$

\subsubsection{Life Insurance Company and Contract}

We model the pricing decision of a single life insurance company that faces exogenous competition in the form of stochastic outside options available to consumers. The market structure can be interpreted as monopolistic competition where the company faces downward-sloping demand due to the imperfect substitutability of insurance policies. ${ }^{15}$

The company faces a stochastic marginal cost shock $c_{o}$ for insuring the old, which is randomly drawn from a continuous and differentiable c.d.f. $G$ and p.d.f. $g$ with support $[\underline{c}, \bar{c}]{ }^{16}$ The marginal cost for each date $c_{j, t}$, where $j \in\{y, o\}$ depends on the aggregate mortality rate and the interest rate. Formally, this relationship can be expressed as

$$
c_{j, t}=\frac{m_{j, t}}{1+i_{t}}
$$

where $i_{t}$ is the one-period risk-free interest rate. We do not take a stand on the distributions of $m_{j, t}$ and $i_{t}$, and instead we only model explicitly the univariate distribution of $c_{j, t}$. Also, since $m_{y, t}$ is small, we assume that $c_{y, t}=c_{y}$ and $m_{y, t}=m_{y}$ for all $t .^{17}$

A key assumption this paper makes is that the cost is privately observed by the insurance company. We find this to be a natural assumption due to the complicated nature of the mapping from interest and mortality rates to the marginal cost of renewable life insurance contracts. This is evidenced by the complex formula for estimating the marginal cost of renewable policies detailed in Appendix C.

We express the set of possible renewal premiums for generation $t$ old consumers as $\left\{P_{o, t+1}\left(c_{o, t+1}\right)\right\}$ and the realization of the premium at cost $c_{o, t+1}$ as $P_{o, t+1}\left(c_{o, t+1}\right)$. This departs from the assumption in Hendel and Lizzeri (2003) and many papers that followed, where policyholders know the renewal premiums as a function of future health upon signing. In this paper, the renewal premium is a function of cost: $P_{o, t+1}:[\underline{c}, \bar{c}] \rightarrow \mathrm{R}_{+}$. However, we refer to it as a set, because cost is not observed by the policyholders and from their perspective the insurers are choosing a premium from a set of admissible renewal premiums (the range

\footnotetext{
${ }^{14}$ It is important to note that since consumers have a positive valuation for having coverage, they are not risk neutral.

${ }^{15}$ This is due to the search and information frictions, as described by Hortacsu and Syverson (2004) and confirmed by the premium dispersion in our dataset. Section 3.1.3 introduces this assumption in more detail.

${ }^{16}$ The insured pool is large, so $G$ does not vary with the size of the insured pool on the margin.

${ }^{17}$ The cost to insure the young is relatively stable in the data, for details see Figure 8 in Section 4.1.
} 
of function $\left.P_{o, t+1}\right)$. The renewable life insurance contract is defined as the premium schedule $\left\{P_{y, t},\left\{P_{o, t+1}\left(c_{o, t+1}\right)\right\}\right\}_{t=0}^{\infty}$, where $P_{y, t}$ is the premium when young.

\subsubsection{Renewability, Transaction Cost and Search Frictions}

There are two types of policies offered in the market: renewable and non-renewable, each with the same face value which we take as given. The young may purchase one of these products, or neither of them. If they choose a renewable policy, then they have an option to renew when old regardless of the possible changes in their health status. On the other hand, a non-renewable policy expires after one period and consumers may purchase another non-renewable insurance bearing the risk of being reclassified to a different health group. In both cases, consumers can lapse after the first period (i.e. drop coverage altogether). ${ }^{18}$

Prior to acquiring a new policy, consumers need to invest a transaction cost $\mu>0$. It captures the cost of researching the market for available products, attending medical checkups, meeting with sales agents and answering detailed questionnaires, as well as being exposed to the contestability period. ${ }^{19}$ If young consumers decide to purchase a non-renewable policy, then they must pay the transaction cost again to receive new coverage when old. On the other hand, this cost is avoided if consumers decide to extend their renewable policy.

In addition to paying $\mu$ again, when old consumers choose to search for a new nonrenewable policy, there are two additional sources of risk associated with this action. First, consumers face a possibility of health deterioration which can result in much higher premium when purchasing non-renewable insurance. ${ }^{20}$ The second source of risk comes from the search and information imperfections, resulting from ample dispersion of the premiums offered in the market. This means that a consumer who decides to search may end up finding a worse alternative, even if the health status is unchanged. To model these risks, the price of nonrenewable insurance for the generation $t$ old consumers is $P_{o, t+1}^{N R}=\epsilon c_{o, t+1}$, where $\epsilon$ is the uncertainty added to the marginal cost and it follows a right-skewed distribution with c.d.f. $Z$ and p.d.f. $z$ and support $(0, \infty)$. As a result, the decision of an old consumers depends on the relative size of the transaction cost, their private valuation of insurance, as well as the risk of searching for a new policy. Since $c_{y}$ is constant, we assume that the non-renewable premiums for the generation $t$ young consumers is constant across time, $P_{y, t}^{N R}=P_{y}^{N R}$.

\footnotetext{
${ }^{18}$ We do not consider the effects of the secondary market, because our quantitative exercise will focus on 30 and 40 year olds and the secondary market usually targets policyholders who have less than 15 years in life expectancy. See Daily et al. (2008); Gottlieb and Smetters (2016); Fang and Kung (2018); Fang and Wu (2019) for in-depth analysis on long-term contract design with secondary markets.

${ }^{19}$ We refer the reader to the quantitative part in Section 4.1.1 for more details on the transaction cost.

${ }^{20} \mathrm{We}$ will abstract from selection issues and assume that the non-renewable premium is independent of the policyholder's valuation.
} 
Most of the literature has focused on the optimal design of long-term contracts with riskaverse agents who face reclassification risk (Hendel and Lizzeri, 2003; Daily et al., 2008; Fang and Kung, 2018). We abstract from this and assume that old consumers are risk neutral with respect to the risk of searching for a new policy $\epsilon$. This is because if consumers are risk averse to reclassification risk, then our theory is strengthened since consumers would be more deterred from searching for new policies and the hold-up problem worsens.

\subsubsection{Timing}

At each $t$, the company announces $P_{y, t}$. Young consumers proceed to make their investment and purchasing decision. Prior to $t+1$, the company announces $\left\{P_{o, t+1}\left(c_{o, t+1}\right)\right\}$. At $t+1, c_{o, t+1}$ is realized and the company sets $P_{o, t+1}$, which all surviving consumers observe. Then, the existing policyholders decide whether to renew, lapse or search for a new offer. ${ }^{21}$ Figure 6 summarizes the timing for generation $t$.

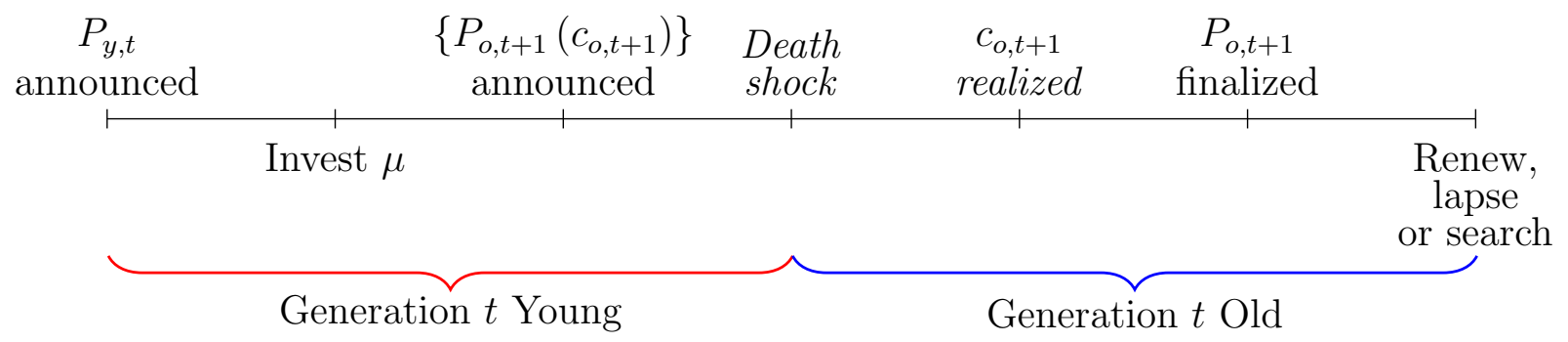

Figure 6: Timing of events

Even though $\left\{P_{o, t+1}\left(c_{o, t+1}\right)\right\}$ is not announced at the beginning of $t$, it is common knowledge that it is selected optimally to balance commitment and discretion. In other words, consumers correctly anticipate $\left\{P_{o, t+1}\left(c_{o, t+1}\right)\right\}$ upon signing. More details will be provided in the following sections.

\subsection{Characterizing the Demand}

For the analysis in this section, we focus on consumers of generation $t$. Let $B^{r e n}\left(r_{o} ; t\right)$ denote the expected utility of a generation $t$ renewable policyholder with private valuation $r_{o}$, and $B^{\text {non }}\left(r_{o} ; t\right)$ denote the expected utility of individuals with the same profile who did

\footnotetext{
${ }^{21}$ We do not model new consumers signing with the firm when they are old. There are two reasons for this. First, if newcomers invest $\mu$ before the realization of $c_{o}$, then the hold-up problem persists, which is a likely concern since $c_{o}$ is volatile as seen in Figure 8. Second, our quantitative exercise will focus on 30-year olds renewing at 40. It is reasonable for the demand of renewing 40-year old policyholders to be larger than the demand of 40-year old new consumers. Therefore, the incentive to exploit held-up policyholders dominates the incentive to lower premiums and attract new consumers.
} 
not purchase a renewable policy. For any $\left\{P_{o, t+1}\left(c_{o, t+1}\right)\right\}$, a generation $t$ consumer with valuation $r_{o}$ purchases renewable life insurance in $t$ if

$$
\begin{aligned}
&\left(r-P_{y, t}-\mu\right)+\left(1-m_{y}\right) \delta B^{r e n}\left(r_{o} ; t\right) \geq \\
& \max \left\{0, r-P_{y}^{N R}-\mu\right\}+\left(1-m_{y}\right) \delta B^{n o n}\left(r_{o} ; t\right)
\end{aligned}
$$

where $B^{r e n}\left(r_{o} ; t\right)$ is

$\int_{\underline{c}}^{\bar{c}} \max \left\{0, r_{o}-P_{o, t+1}\left(c_{o, t+1}\right), \int_{\epsilon} \max \left\{0, r_{o}-P_{o, t+1}\left(c_{o, t+1}\right), r_{o}-P_{o, t+1}^{N R}\right\} d Z(\epsilon)-\mu\right\} d G\left(c_{o, t+1}\right)$

and

$$
B^{n o n}\left(r_{o} ; t\right)=\int_{\underline{c}}^{\bar{c}} \max \left\{0, \int_{\epsilon} \max \left\{0, r_{o}-P_{o, t+1}^{N R}\right\} d Z(\epsilon)-\mu\right\} d G\left(c_{o, t+1}\right) .
$$

There are three benefits to purchasing a renewable policy, all reflected in the left-hand side of (1). First, renewable policyholders do not need to incur a transaction cost of $\mu$ if they renew. Second, renewable life insurance contracts are similar to options. Due to one-sided commitment, policyholders are not obligated to renew if premiums are high. They could instead lapse or search for a new policy. Finally, policyholders can always renew if they are unable to find better deals after searching. The right-hand side of (1) captures the expected utility of not purchasing a renewable. In this case, individuals can choose to either not have coverage or be covered by a non-renewable when young. When they are old, they have the same options as renewable policyholders except for the option of renewing. We will make the following assumption, so all consumers would have coverage when young. ${ }^{22}$

Assumption $1 r \geq P_{y}^{N R}+\mu$.

By Assumption 1, a generation $t$ young consumer purchases renewable if and only if

$$
B^{r e n}\left(r_{o} ; t\right)-B^{n o n}\left(r_{o} ; t\right) \geq \frac{P_{y, t}-P_{y}^{N R}}{\left(1-m_{y}\right) \delta}
$$

Inequality (2) states that consumers purchase renewable insurance if and only if the additional expected benefit in owning a renewable when old is greater than the premium difference of the two types of insurance when young. The next lemma helps characterize the demand.

\footnotetext{
${ }^{22}$ This simplifies but does not change our analysis, because as long as $\mu$ is sufficiently large the hold-up problem persists.
} 
Lemma 1 For any $t, B^{\text {ren }}\left(r_{o} ; t\right)$ and $B^{\text {non }}\left(r_{o} ; t\right)$ have the following properties: (i.) $B^{\text {ren }}\left(r_{o} ; t\right) \geq B^{\text {non }}\left(r_{o} ; t\right) \geq 0$ for all $r_{o}$, (ii.) $B^{\text {ren }}\left(r_{o} ; t\right)$ and $B^{\text {non }}\left(r_{o} ; t\right)$ are weakly increasing in $r_{o}$, (iii.) there exists sufficiently large $\tilde{r}_{o}$ such that $B^{r e n}\left(r_{o} ; t\right)$ and $B^{\text {non }}\left(r_{o} ; t\right)$ are strictly increasing in $r_{o}$ for any $r_{o} \geq \tilde{r}_{o}$. Also, if there exists $\hat{r}_{o}$ such that $B^{\text {ren }}\left(\hat{r}_{o} ; t\right)>B^{\text {non }}\left(\hat{r}_{o} ; t\right)$, then $B^{r e n}\left(r_{o} ; t\right)-B^{n o n}\left(r_{o} ; t\right)$ is strictly increasing in $r_{o} \geq \hat{r}_{o}$.

Lemma 1 states that if there are consumers who prefer renewables, then all consumers with higher $r_{o}$ would also prefer renewables. If $P_{y, t} \leq P_{y}^{N R}$, then (2) is automatically satisfied. In particular, the demand for renewables is independent of $r_{o}$, because consumers purchase renewables as long as $r \geq P_{y, t}+\mu$ regardless of $r_{o}$. As a result, not all renewable policyholders expect to renew next period. Hence, there is no hold-up problem if $P_{y, t} \leq P_{y}^{N R}$, because the renewal demand is elastic with respect to premium changes.

The more interesting case is when $P_{y, t}>P_{y}^{N R}$, because all renewable policyholders expect to renew. This means only consumers with sufficiently large $r_{o}$ would purchase renewables (by Lemma 1) and there is a lower bound in $r_{o}$ for its pool of policyholders (by (2)). The firm would then be tempted to increase $P_{o, t+1}$ to this lower bound. This is because the renewal demand in $t+1$ is inelastic with respect to premium changes below this lower bound. The firm encounters a hold-up problem when $P_{y, t}>P_{y}^{N R}$. We will show numerically that despite this, the firm will set $P_{y, t}>P_{y}^{N R}$ at the optimum.

More formally, let $\bar{r}_{o}\left(P_{y, t},\left\{P_{o, t+1}\left(c_{o, t+1}\right)\right\}\right)$ be defined as the threshold valuation such that (2) holds with equality. Notice that this threshold is increasing with respect to both premiums. To streamline notation, we write $\bar{r}_{o, t}$ with the implicit understanding that it depends on the premium schedule. Lemma 1 shows that all consumers with $r_{o} \geq \bar{r}_{o, t}$ purchase the renewable insurance. The demand function of generation $t$ young consumers is

$$
D_{y, t}\left(P_{y, t},\left\{P_{o, t+1}\left(c_{o, t+1}\right)\right\}\right)=1-H\left(\bar{r}_{o, t}\right) .
$$

The demand for renewing is

$$
D_{o, t+1}\left(P_{y, t}, P_{o, t+1}\left(c_{o, t+1}\right)\right)=\left(1-m_{y}\right)\left[1-H\left(\max \left\{\bar{r}_{o, t}, P_{o, t+1}\left(c_{o, t+1}\right)\right\}\right)\right] .
$$

The demand is weakly decreasing in premiums. Most importantly, renewal demand becomes perfectly inelastic for any $P_{o, t+1}\left(c_{o, t+1}\right) \leq \bar{r}_{o, t}$.

\subsection{Incentive Compatibility}

Before a young consumer buys a renewable policy, the renewal demand is downward sloping for all premiums. We refer to this pre-investment demand as the ex-ante demand 
and the demand following the signing of the contract as the ex-post demand. The ex-ante and ex-post demands are different which creates a time inconsistency problem for the insurance company. In particular, policyholders reveal their valuation is at least as large as $\bar{r}_{o, t}$ by purchasing. After consumers sign, the insurance company has an incentive to increase next period premiums up to $\bar{r}_{o, t}$, because the renewal demand is inelastic for prices below it.

The disparity between the ex-ante and the ex-post demand is the reason why the insurance company needs commitment. However, volatile cost shocks create an incentive to adjust premiums accordingly. To resolve this tension, the insurance company disciplines its pricing behavior by making sure $\left\{P_{o, t+1}\left(c_{o, t+1}\right)\right\}$ is incentive compatible for all generations.

For generation $t$ old policyholders, we can define the following cost regions for $c_{o, t+1}$ :

$$
\begin{aligned}
& \overline{\mathcal{C}}_{o, t+1}=\left\{c_{o, t+1} \mid P_{o, t+1}\left(c_{o, t+1}\right) \geq \bar{r}_{o, t}\right\}, \\
& \underline{\mathcal{C}}_{o, t+1}=\left\{c_{o, t+1} \mid P_{o, t+1}\left(c_{o, t+1}\right)<\bar{r}_{o, t}\right\} .
\end{aligned}
$$

It is worth pointing out that the dissonance between ex-ante and ex-post demands occurs for $c_{o, t+1} \in \underline{\mathcal{C}}_{o, t+1}$, while both demands are in agreement for $c_{o, t+1} \in \overline{\mathcal{C}}_{o, t+1}{ }^{23}$

We require $\left\{P_{o, t+1}\left(c_{o, t+1}\right)\right\}$ to be incentive compatible: for all $t$ and all $c_{o, t+1}, c_{o, t+1}^{\prime} \in[\underline{c}, \bar{c}]$,

$$
\begin{aligned}
{\left[P_{o, t+1}\left(c_{o, t+1}\right)-c_{o, t+1}\right] D_{o, t+1}\left(P_{y, t}, P_{o, t+1}\left(c_{o, t+1}\right)\right) } & \geq \\
{\left[P_{o, t+1}\left(c_{o, t+1}^{\prime}\right)\right.} & \left.-c_{o, t+1}\right] D_{o, t+1}\left(P_{y, t}, P_{o, t+1}\left(c_{o, t+1}^{\prime}\right)\right) .
\end{aligned}
$$

Constraint (5) serves to reduce the possible set of renewal premiums $\left\{P_{o, t+1}\left(c_{o, t+1}\right)\right\}$ the company can choose from after realizing the cost. This is the same concept as delegation sets in Holmstrom (1984). The set is announced prior to $t+1$. Though the set of premiums is not legally binding, the firm has reputational concerns stemming from the fact that deviating from this set would instigate retaliation from future generations which lowers its expected discounted profit. The reputation mechanism is explored in detail in Appendix F. For the remainder of the paper, we analyze the environment where a sufficiently large exogenous cost is imposed on the insurer for deviating from $\left\{P_{o, t+1}\left(c_{o, t+1}\right)\right\}$ for any $t+1$.

In addition to incentive compatibility, the company needs to refrain from exploiting the consumers. The additional disciplinary measure requires the life insurance company to take $\bar{r}_{o, t}$ as given and choose $\left\{P_{o, t+1}\left(c_{o, t+1}\right)\right\}$ such that $(2)$ is satisfied for all $r_{o} \geq \bar{r}_{o, t}$. In essence, the company needs to deliver a minimal expected utility to the policyholders that corresponds to what the consumers expected when they were young.

\footnotetext{
${ }^{23}$ The analysis does not change if $\overline{\mathcal{C}}_{o, t+1}=\left\{c_{o, t+1} \mid P_{o, t+1}\left(c_{o, t+1}\right)>\bar{r}_{o, t}\right\}$ and $\underline{\mathcal{C}}_{o, t+1}=$ $\left\{c_{o, t+1} \mid P_{o, t+1}\left(c_{o, t+1}\right) \leq \bar{r}_{o, t}\right\}$.
} 


\subsection{The Optimization Problem}

From our model's setup, we can see that the insurance company maximizes the expected present value of profits by optimizing the profit for each generation, and that the optimal premium schedule is stationary. Hence, the company can maximize total expected presentvalued profit by choosing the same premium schedule $\left(P_{y},\left\{P_{o}\left(c_{o, t+1}\right)\right\}\right)$ for each generation $t$. This is because the environment is the same across generations, so the firm's problem does not change for each generation. The analysis will thus focus on the company maximizing its profit from a single generation. To simplify notation, we drop the date subscripts.

We consider a sequentially optimal pricing rule. The company chooses a premium function in each period that maximizes the present value of discounted profits taking into account that it will do the same in the future. Moreover, consumers purchase insurance taking the future behavior of the company into consideration. The endogeneity of consumer behavior differs from the concept of sequential optimality in Halac and Yared (2014).

Definition 1 The sequentially optimal pricing rule is a contract $\left\{P_{y},\left\{P_{o}\left(c_{o}\right)\right\}\right\}$ such that $\left\{P_{o}\left(c_{o}\right)\right\}$ solves the static optimization problem:

$$
\Pi_{o}\left(P_{y}\right) \equiv \max _{\left\{P_{o}\left(c_{o}\right)\right\}} \int_{\underline{c}}^{\bar{c}}\left(P_{o}\left(c_{o}\right)-c_{o}\right) D_{o}\left(P_{y}, P_{o}\left(c_{o}\right)\right) d G\left(c_{o}\right),
$$

subject to (2) and (5) for any given $P_{y}$ and $\bar{r}_{o}$. The premium $P_{y}$ solves the optimization problem for a given $c_{y}$ by taking the optimal response $\left\{P_{o}\left(c_{o}\right)\right\}$ as given:

$$
\Pi=\max _{P_{y}}\left(P_{y}-c_{y}\right) D_{y}\left(P_{y},\left\{P_{o}\left(c_{o}\right)\right\}\right)+\frac{1}{1+i} \Pi_{o}\left(P_{y}\right) .
$$

Given $P_{y}$ and the optimal response $\left\{P_{o}\left(c_{o}\right)\right\}$, consumers sign-up for renewable life insurance if (2) is satisfied.

We choose to focus on the sequentially optimal pricing rule instead of the ex-ante optimal pricing rule, where the company chooses the current and all future premium schedules at the beginning of the generation, because companies may choose to renegotiate or announce possible changes to the premiums before the following period. For example, the premium schedule in Table 1 demonstrates how, in practice, life insurance companies do not tie themselves down to a fixed pricing rule.

The objective (6) is similar to finding a balance between discretion versus rules in delegation problems. The main difference is in how this trade-off is being created. The literature on optimal delegation and self-control has focused on situations where the disagreement between principal and agent or present and future-selves is exogenous. In (7), the insurance 
company can completely eliminate its time inconsistency by setting $P_{y} \leq P_{y}^{N R}$. However, we will show numerically that the trade-off in life insurance contracts is endogenously generated by the company optimally setting $P_{y}>P_{y}^{N R} \cdot{ }^{24}$

\section{The Optimal Premium Schedule}

In this section, we characterize the incentive compatible set of premiums $\left\{P_{o}\left(c_{o}\right)\right\}$ and obtain its general properties. Note that all of the results here are for $P_{y}>P_{y}^{N R}$. Later in this section, we will calibrate the model and solve for $P_{y}$. The following lemma shows that the incentive compatible $\left\{P_{o}\left(c_{o}\right)\right\}$ is rigid for low cost shocks.

Lemma 2 An incentive compatible $\left\{P_{o}\left(c_{o}\right)\right\}$ satisfies the following:

i. For $c_{o} \in \underline{\mathcal{C}}_{o}, P_{o}\left(c_{o}\right)$ does not vary with $c_{o}$ and $\underline{\mathcal{C}}_{o}$ has strictly positive measure.

ii. $P_{o}\left(c_{o}\right)$ is weakly increasing, and there exists $c^{T}$ such that $\underline{\mathcal{C}}_{o}=\left[\underline{c}, c^{T}\right)$ and $\overline{\mathcal{C}}_{o}=\left[c^{T}, \bar{c}\right]$.

Lemma 2 shows that incentive compatible renewal premiums do not respond to small cost shocks: $c_{o} \in \underline{\mathcal{C}}_{o}=\left[\underline{c}, c^{T}\right)$. The rigidity is caused by the inelastic renewal demand prices below $\bar{r}_{o}$. However, the firm knows the minimum valuation $\bar{r}_{o}$ of the insured pool from (2) and is tempted to increase premiums up to it. As a result, any variation in premiums below $\bar{r}_{o}$ would not be credible, because the firm would always announce the highest premium below $\bar{r}_{o}$.

Denote $\bar{P}_{o}=P_{o}\left(c_{o}\right)$ and the demand $\bar{D}_{o}=D_{o}\left(P_{y}, P_{o}\left(c_{o}\right)\right)$ for all $c_{o} \in \underline{\mathcal{C}}_{o}$. Lemma 2 allows us to rewrite the downward deviating incentive compatibility constraints into the following single constraint: $\forall c_{o} \in \overline{\mathcal{C}}_{o}, \forall c_{o}^{\prime} \in \underline{\mathcal{C}}_{o},\left[P_{o}\left(c_{o}\right)-c_{o}\right] D_{o}\left(P_{y}, P_{o}\left(c_{o}\right)\right) \geq\left(\bar{P}_{o}-c_{o}^{\prime}\right) \bar{D}_{o}$. Similarly, we can also rewrite the upward deviating incentive compatibility constraints. In particular, we have the following binding incentive compatibility constraint at $c^{T}$ :

$$
\left(\bar{P}_{o}-c^{T}\right) \bar{D}_{o}=\left(P_{o}\left(c^{T}\right)-c^{T}\right)\left[1-H\left(P_{o}\left(c^{T}\right)\right)\right]
$$

If (8) is non-binding, then it is not incentive compatible for $c_{o}$ within a neighborhood of $c^{T}$.

The next lemma characterizes the incentive compatible premium for $\overline{\mathcal{C}}_{o}$, which shows that premiums are also rigid for intermediate cost shocks. Let $P_{o}^{*}\left(c_{o}\right)$ denote the optimal

\footnotetext{
${ }^{24}$ An additional reason for $P_{y}>P_{y}^{N R}$ not modeled in this paper is the fact that firms may attempt to screen consumers with demand in the next period from those without. To see this, suppose some consumers have $r_{o}=0$ while some have $r_{o}>0$. The firm separates the two types by issuing renewable and non-renewable contracts. Consumers with $r_{o}=0$ prefer the non-renewables $r-P_{y}^{N R}-\mu \geq r-P_{y}-\mu+\delta \eta$, where $\eta>0$ is the expected benefit from selling the insurance in the secondary market. This implies $P_{y}-P_{y}^{N R} \geq \delta \eta$.
} 
frictionless premium at $c_{o}$. We refer to it as the frictionless premium because the incentive compatibility constraints are not binding.

Lemma 3 An incentive compatible $\left\{P_{o}\left(c_{o}\right)\right\}$ satisfies the following:

i. For $c_{o} \in \overline{\mathcal{C}}_{o}$, if $P_{o}\left(c_{o}\right)$ is strictly increasing and continuous on an open interval $\left(c_{o}^{\prime}, c_{o}^{\prime \prime}\right)$, then $P_{o}\left(c_{o}\right)=P_{o}^{*}\left(c_{o}\right)$ on $\left(c_{o}^{\prime}, c_{o}^{\prime \prime}\right)$.

ii. There is a discrete jump in premiums at $c^{T}: P_{o}\left(c^{T}\right)>\bar{r}_{o}>\bar{P}_{o}$. Furthermore, there exists $c^{M}>c^{T}$ such that $P_{o}\left(c_{o}\right)$ does not vary with $c_{o} \in\left[c^{T}, \min \left\{c^{M}, \bar{c}\right\}\right)$.

Lemma 3 shows that the company charges the optimal frictionless price if it has full flexibility, but it is not incentive compatible for the firm to have full flexibility for all costs in $\overline{\mathcal{C}}_{o}$. Most importantly, Lemma 3 shows that $\left\{P_{o}\left(c_{o}\right)\right\}$ has a jump discontinuity at $c^{T}$. In essence, the incentive compatible premium has to have a discrete jump if the company has flexibility to adjust premiums. What is interesting is the size of this jump. The jump at $c^{T}$ is such that $P_{o}\left(c^{T}\right)>\bar{r}_{o}$, because the company has to induce enough lapsation to convince the consumers that an upward adjustment in premiums is due to adverse cost shocks and not an attempt to take advantage of the hold-up problem. The company can credibly respond to cost shocks only when it causes a simultaneous decrease in the demand for insurance.

The existence of a discontinuous jump is in contrast to the optimal delegation literature, where general conditions can be found to rule it out (Amador and Bagwell, 2013). The difference is the endogeneity of $\bar{r}_{o}$. To see why, suppose the admissible premium is within the range of $[A, B]$, then only consumers with $r_{o}>B$ would purchase renewables. ${ }^{25}$ Therefore, $\bar{r}_{o}>B$ and the company would always charge a price of $B$. This implies that incentive compatible adjustments to premiums have to be significant and contain jumps.

Lemma 3 also states that incentive compatible premiums are rigid for $c_{o} \in$ $\left[c^{T}, \min \left\{c^{M}, \bar{c}\right\}\right)$. This is because if the firm chooses $P_{o}^{*}\left(c_{o}\right)$ for all $c_{o} \in\left[c^{T}, \bar{c}\right]$, then the firm would deviate to the frictionless premium for cost shocks slightly below $c^{T}$. As a result, the firm chooses a rigid premium, which is the only other incentive compatible option for costs within $\left[c^{T}, \min \left\{c^{M}, \bar{c}\right\}\right) .{ }^{26}$ This implies the firm is able to charge frictionless premiums only for sufficiently large shocks, because the corresponding frictionless premiums are large enough to cause a significant decrease in demand through lapsation to retain incentive compatibility. Let $\overline{\bar{P}}_{o}$ denote the rigid premium when $c_{o} \in\left[c^{T}, \min \left\{c^{M}, \bar{c}\right\}\right)$.

\footnotetext{
${ }^{25}$ Consumers with $r_{o}=A$ would purchase non-renewables, because expected utility for buying renewables would be zero. Also, consumers with $r_{o} \in(A, B]$ would also not purchase, because the company would set $P_{o}=\bar{r}_{o}$ if they are part of the insured pool making $[A, B]$ not incentive compatible.

${ }^{26}$ This result is similar to the characterization of incentive compatible delegation rules with discontinuities in Melumad and Shibano (1991) and Alonso and Matouschek (2008).
} 
Theorem 1 The incentive compatible premium has the following feature:

$$
P_{o}\left(c_{o}\right)= \begin{cases}\bar{P}_{o} & \underline{c} \leq c_{o}<c^{T} \\ \overline{\bar{P}}_{o} & c^{T} \leq c_{o}<\min \left\{c^{M}, \bar{c}\right\} \\ P_{o}^{*}\left(c_{o}\right) & \min \left\{c^{M}, \bar{c}\right\} \leq c_{o} \leq \bar{c}\end{cases}
$$

with $\bar{P}_{o}<\bar{r}_{o}<\overline{\bar{P}}_{o}=P_{o}^{*}\left(c^{M}\right)$ and

$$
\left(\bar{P}_{o}-c^{T}\right)\left[1-H\left(\bar{r}_{o}\right)\right]=\left(\overline{\bar{P}}_{o}-c^{T}\right)\left[1-H\left(\overline{\bar{P}}_{o}\right)\right]
$$

Theorem 1 shows that the incentive compatible set of renewal premiums $\left\{P_{o}\left(c_{o}\right)\right\}$ is $\left\{\bar{P}_{o},\left[\overline{\bar{P}}_{o}, P_{o}^{*}(\bar{c})\right]\right\}$, so the insurer does not announce premiums within $\left(\bar{P}_{o}, \overline{\bar{P}}_{o}\right)$. Figure 7 illustrates an optimal incentive compatible pricing rule. By Theorem 1, the life insurance company solves for the premiums $\left\{\bar{P}_{o}, \overline{\bar{P}}_{o}, P_{y}\right\}$ and the cost thresholds $\left\{c^{T}, c^{M}\right\}$ subject to (2) and (9). Since the premiums affect $\bar{r}_{o}$ and vice versa, the optimization problem is complex and it is difficult to obtain tractable analytical solutions. In the next subsection, we solve the model numerically.

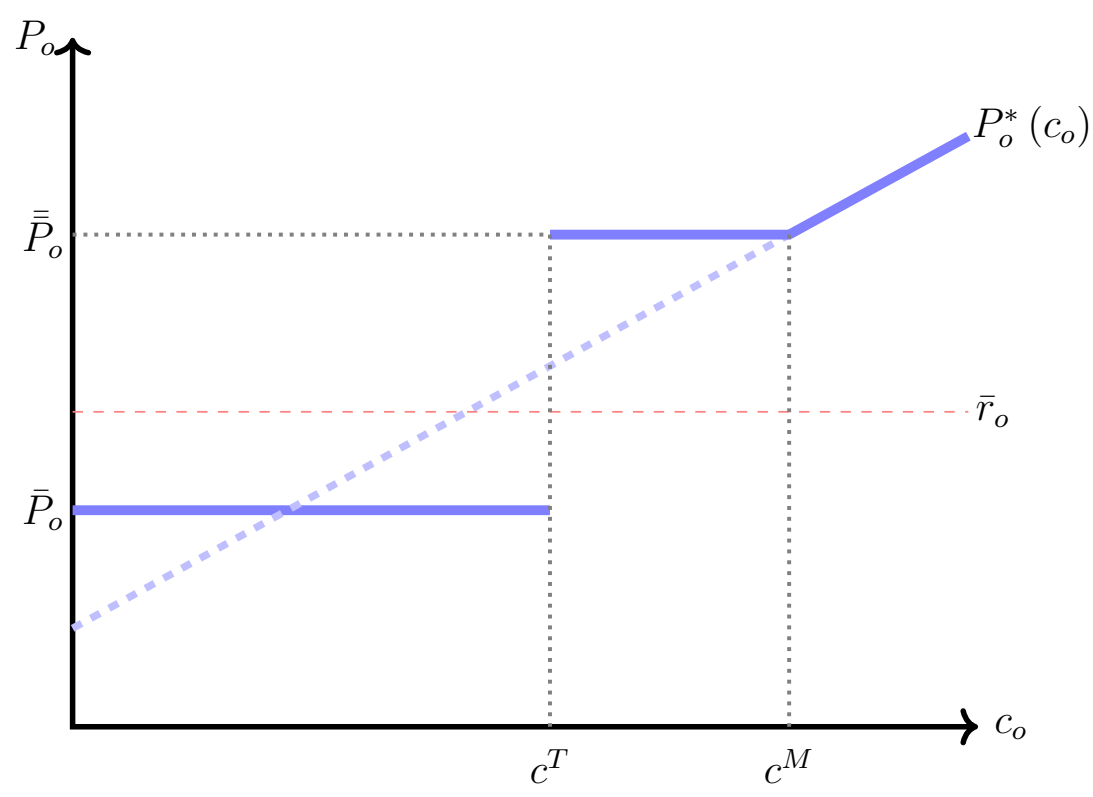

Figure 7: Incentive compatible premium profile 


\subsection{Numerical Analysis}

\subsubsection{Calibration}

The model does not have an explicit closed-form solution. ${ }^{27}$ We proceed by using the data and outside knowledge to assume reasonable parameter values and functional forms, and solve for an equilibrium numerically. Table 3 presents a summary of our calibration. Because we only focus on two periods, we assume that each period is equivalent to ten years and calibrate the remaining parameters to the features of ten-year level-term renewable insurance. While most of the model variables do not have a direct counterpart in the data, we attempt to make the calibration realistic while also keeping the numerical solution feasible. In what follows we describe our assumptions on the functional forms and parameter values.

Table 3: Parameter values in the model

\begin{tabular}{lll}
\hline Symbol & Meaning & Value \\
\hline$\mu$ & Transaction cost & 970 \\
$c_{y}$ & Cost shock for insuring young & 1090 \\
$P_{y}^{N R}$ & Price of non-renewable insurance & 1040 \\
$m_{y}$ & Mortality rate & 0.007 \\
$i$ & Annual interest rate & 0.04 \\
$\delta$ & Discount factor & 0.68
\end{tabular}

Cost shock distribution: uniform

\begin{tabular}{lll}
\hline $\bar{c}$ & Lower bound & 2700 \\
$\underline{c}$ & Upper bound & 3500
\end{tabular}

Valuation distribution: Generalized Pareto

\begin{tabular}{lll}
\hline$\gamma$ & Scale parameter & 700 \\
$\kappa$ & Shape parameter & 0 \\
$\theta$ & Threshold parameter & 3595
\end{tabular}

Search and health shock distribution: lognormal

\begin{tabular}{lll}
\hline $\bar{\epsilon}$ & Mean & -0.0104 \\
$\sigma_{\epsilon}$ & Standard deviation & 0.14425 \\
\hline
\end{tabular}

The marginal cost to insure a consumer is computed directly from the data. Cost of covering the young $c_{y}$ corresponds to the average expected death benefit payout for a 30-

\footnotetext{
${ }^{27}$ This is mainly because $\bar{r}_{o}$ affects the degree of rigidity and the size of the discrete jump, but it is also endogenously determined by the premiums.
} 
year old male over the period of ten years. ${ }^{28}$ This cost ranges from $\$ 914$ to $\$ 1244$ in the data, with a mean of $\$ 1090$. Because of the relatively small volatility of this variable evident in Figure 8 below, we simplify the model by taking $c_{y}$ as given and setting it equal to the average. The cost of covering the old $c_{o}$ is associated with the expected death benefit payout for a 40-year old male who is renewing a policy purchased at age 30. This involves using different (higher) mortality rates than for new 40-year-old customers who have just passed a medical exam. This cost ranges from $\$ 2717$ to $\$ 3430$ in the data, with an average of $\$ 3064$. The distribution of this shock is unlikely to be normal due to the presence of fat tails. This is confirmed by the Jarque-Bera test which returns a p-value of 0.075 , providing grounds to reject the null hypothesis of normality. In order to make computation of some parts of the equilibrium analytically feasible, we assume that the distribution is uniform with bounds $[2700,3500]$. Figure 8 illustrates our measure of the cost shocks over time. ${ }^{29}$

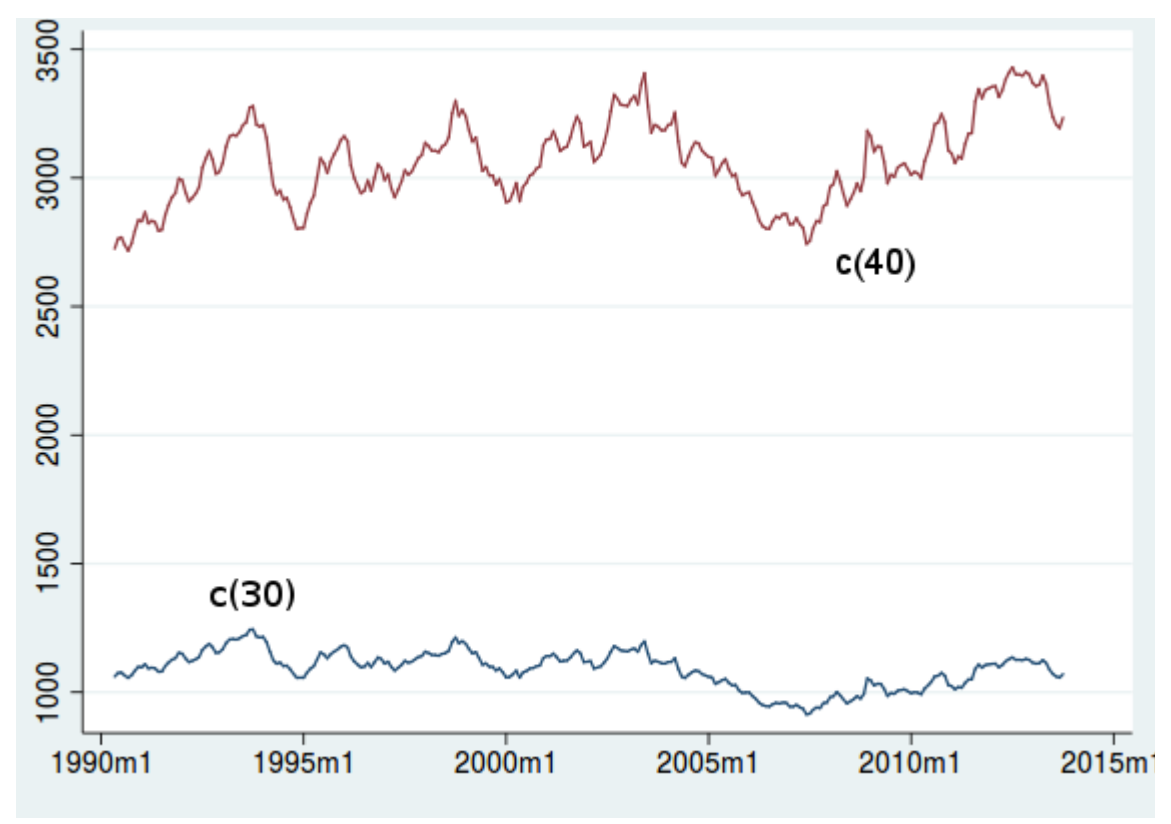

Figure 8: Cost shocks in the data

The distribution of consumers' private valuations does not have a clear counterpart in the data. To simplify the algorithm, we assume it to be a Generalized Pareto distribution, with the shape parameter of 0 . This assumption makes it essentially a "shifted" exponential distribution, which features a constant inverse hazard rate $\frac{1-H(\cdot)}{h(\cdot)}=\gamma$, enabling us to obtain closed-form solutions for prices $\bar{P}_{o}$ and $\overline{\bar{P}}_{o}$ (details of the solution method are provided in

\footnotetext{
${ }^{28}$ As discussed in Appendix C, we abstract here from the issue of voluntary lapsation and assume that the consumer will continue to pay the premium for the entire period.

${ }^{29}$ In reference to the series presented in Figure 5, here we consider a fixed 10-year insurance term only and do not convert the cost shocks to annual values.
} 
Appendix E). The scale parameter $\gamma$ is selected to match the existing evidence on elasticity of demand for term life insurance. Specifically, Pauly et al. (2003) use the Compulife data from January 1997 and find the price elasticity of demand to be 0.475 for a median company. Given our distributional assumption, and the median yearly premium for an ART in January 1997 of $\$ 335$, we set the value of the scale parameter $\gamma$ to be 700 . The threshold parameter $\theta$ is then calibrated to match the fraction of non-renewable policies among all term policies underwritten, equal to $11 \%$ as reported by LIMRA (1994).

The distribution of the health and search shock $\epsilon$ is assumed to be lognormal, which conveniently allows us to calculate the integrals inside of $B^{r e n}(\cdot)$ and $B^{\text {non }}(\cdot)$ of (1) analytically, rather than numerically. The right skewness of the distribution captures the idea that a consumer who decides to search for a new policy when old may find a better deal in the market, but is also at a risk of prohibitive premium increases should his health have deteriorated or lifestyle habits changed. ${ }^{30}$ We do not have compelling evidence on the probabilities of getting a table rating. For this reason, we set the parameters of the lognormal distribution to match two moments: i.) $E(\epsilon)=1$, and ii.) $\operatorname{Var}(\epsilon)=0.145^{2}$ where 0.145 is the average coefficient of variation across time for all the prices of 10-year renewable term policies in our sample. In other words, we calibrate the variance of search shocks to match the observed dispersion of premiums in the data, and allow the right-skewness of the lognormal distribution to determine the likelihood of adverse health shocks. Notice that by calibrating the distribution of $\varepsilon$ to the empirical price dispersion, we introduce to the model a reduced-form effect of market competition (Section 5.5.3 provides more evidence on this).

The transaction (or switching) cost $\mu$ is the key parameter in our model, and at the same time probably the most controversial one. It comprises the opportunity cost of researching the products on the market (and not working or using leisure), the opportunity and monetary cost of attending the medical examination, the opportunity cost of meeting with an insurance agent and filling out the paperwork (in particular given that our sample starts in 1990s). Additional factors contributing to the dollar value of $\mu$ consist of the cognitive cost of shopping for an insurance policy and undertaking a long-term commitment (for example, overcoming cognitive dissonance), as well as getting exposure to the contestability period, i.e. a possibility that the insurance company may reject a benefit claim if death occurs in a short period after signing the contract. Direct estimation of switching costs in the life insurance market is beyond the scope of this paper. Instead, we survey the literature for similar recent estimates across other markets which also feature long-term contracts. Table 4 summarizes

\footnotetext{
${ }^{30}$ In practice, below the regular health category life insurance companies use the so-called table ratings to determine a premium hike. The consumer's health and lifestyle is evaluated with respect to several categories and each one may raise the standard rate by $25 \%$.
} 
our investigation. The switching cost estimates vary significantly for different studies and markets, ranging between $\$ 40$ and $\$ 700$ for markets such as auto insurance, wireless or cable TV, as well as between $\$ 1200$ and $\$ 5000$ for health and retirement plans. In order not to rely on possibly irrelevant outliers, we adopt a median value between these two groups of $\$ 970$, and we analyze the importance of this parameter by performing comparative statics exercises in the following section.

Table 4: Switching cost estimates in the related literature

\begin{tabular}{lll}
\hline Reference & Market & Dollar value \\
\hline Honka (2014) & Auto insurance & $45-190$ \\
Cullen and Shcherbakov (2010) & Wireless & 255 \\
Shcherbakov (2016) & Television and satellite & $227-395$ \\
Weiergräber (2014) & Wireless & $337-672$ \\
Illanes (2016) & Pension plans & 1285 \\
Miller and Yeo (2018) & Medicare & $1700-1930$ \\
Handel (2013) & Health insurance & 2250 \\
Nosal (2012) & Medicare & 4990 \\
\hline
\end{tabular}

Note: Relative to the amounts quoted in original papers, we convert them to 2012 US dollars.

The remaining parameters of the model are calculated directly from the data. The mortality rate $m_{y}$ is the cumulative ten-year probability of dying for the insured 30-year old male; we find it to be $0.7 \%$ using the 2001 Select and Ultimate mortality tables. The annual interest rate $i$ is assumed to be $4 \%$, which yields the ten-year discount factor $\delta$ of 0.68 . Finally, we assume that the non-renewable insurance premium $P_{y}^{N R}$ is $\$ 1040$, which implies that such policies are priced competitively and sold at a slight discount relative to the cost of renewables $c_{y}$. This assumption is useful in the model due to the fact that the firm may choose $P_{y}=P_{y}^{N R}$ to eliminate its time inconsistency problem. However, with $c_{y}>P_{y}^{N R}$, this will cause a loss in covering the young encouraging the firm to seek an interior solution instead. Empirically, the assumption that non-renewable insurance is sold at a discount relative to the ten-year marginal cost is plausible for at least two reasons. First, consumers who purchase such policies are likely to actually need it for a shorter time, resulting in higher lapsation rates. Second, the average health status of renewable policyholders at any given time tends to be worse than non-renewable policyholders. This is because all non-renewable policyholders recently had health exams, while some renewable policyholders have renewed without undergoing a health exam and have likely deteriorated in health. For example, in the data the cost to insure a pool of 30-year-olds who have held their policies for 10 years increases the marginal cost by $55 \%$. While in reality such vintage policyholders are likely a 
minority in the pool of 30-year-old customers, their existence naturally elevates the average cost $c_{y}$ relative to $P_{y}^{N R}$, a price only available to the newcomers.

\subsubsection{The Equilibrium}

Table 5 presents the equilibrium of our model under the discussed calibration. The upper cost threshold $c^{M}$ is optimally set equal to the upper bound of the cost distribution, $\bar{c}$. This means that the premiums can only be one of two values: $\bar{P}_{o}$ and $\overline{\bar{P}}_{o}$. The lower cost threshold $c^{T}$ is equal to 3054.47, roughly in the middle of the cost domain. This frequency of price adjustments is reasonable given that we calibrate the model to 10-year renewable level-term insurance. The predicted rigid premiums, $\bar{P}_{o}$ and $\overline{\bar{P}}_{o}$, are equal to 3626.22 and 4074.47, respectively. As the lower panel of Table 5 shows, this is well in the ballpark of what the renewing 40-year-olds can expect to pay in the data (expressed in cumulative ten-year terms). Also, the size of the jump predicted by our model, $\left(\overline{\bar{P}}_{o} / \bar{P}_{o}-1\right) \times 100$, matches closely the average size of the premium adjustment observed in the data, around $12 \%$.

Table 5: Equilibrium of the model

\begin{tabular}{llr}
\hline Symbol & Variable name & Value \\
\hline$\Pi$ & Total profit & 310.93 \\
$\Pi_{o}$ & Profit from old & 511.21 \\
$c^{T}$ & Lower cost threshold & 3054.47 \\
$c^{M}$ & Upper cost threshold & 3500.00 \\
$P_{y}$ & Price for young & 1050.89 \\
$\bar{P}_{o}$ & Lower price for old & 3626.22 \\
$\bar{r}_{o}$ & Threshold for renewables & 3669.27 \\
$\overline{\bar{P}}_{o}$ & Upper price for old & 4074.47 \\
$\left(\overline{\bar{P}}_{o} / \bar{P}_{o}-1\right) \times 100$ & Jump between premiums (in \%) & 12.36 \\
\hline
\end{tabular}

\section{Premiums in the data:}

40-year-old average

40-year-old median

40-year-old standard deviation

817.93

Average change (in \%)

Note: the data section summarizes the premiums for 40-year-old males in regular health category, for 10-year renewable insurance. Annual premiums are expressed here as present expected value of the entire ten-year period, until renewal. Similarly as in section 2.4, we ignore the issue of lapsation. 


\subsubsection{Comparative Statics}

We now analyze the mechanics of the model by performing several comparative statics exercises with respect to the key parameters. Figure 9 illustrates how the optimal pricing rule changes with transaction cost $\mu$. Renewable life insurance contracts become more attractive compared to non-renewables as $\mu$ increases. The firm responds by increasing premiums $\left(P_{y}\right.$, $\bar{P}_{o}$ and $\overline{\bar{P}}_{o}$ ) and restricting quantity, i.e. the pool of covered policyholders ( $\bar{r}_{o}$ increases). As a result, the total profit of the firm rises. Crucially though, an increase in the transaction cost also worsens the hold-up problem. In order to attract consumers ex ante, the firm responds by increasing $c^{T}$ so that it is more committed to the low premium $\bar{P}_{o}$, and by raising the size of the jump up to the high premium $\overline{\bar{P}}_{o}$. Notice that beyond a certain level of $\mu$, the terms of the optimal contract become invariant. This is due to the fact that search becomes too expensive for a vast majority of consumers and only the ones with high enough demand for coverage when old decide to buy.

Figure 10 shows a similar exercise when we vary the mode of the lognormal health and search shock distribution, while holding the mean equal to 1 . Higher mode means that consumers face more adverse health shocks and become more locked-in to the contract, but it also makes renewables more desirable than non-renewables. Once again, the decrease in competition from non-renewables leads the firm to raise equilibrium premiums and restrict the quantity supplied. By the same logic as with the transaction cost, to attract more consumers ex ante the equilibrium cost threshold $c^{T}$ goes up, promising a wider interval of rigid low-price insurance, and the jump between $\overline{\bar{P}}_{o}$ and $\bar{P}_{o}$ widens.

Finally, in Figure 11 we vary the inverse hazard rate of the distribution of consumers' valuations. As $\gamma$ goes up, the price elasticity of demand decreases and the company enjoys more monopoly power resulting in a higher $\bar{P}_{o}$. Importantly though, lower demand elasticity does not alter the strength of the consumers' hold-up problem and as a result the equilibrium cost threshold falls, imposing high premiums over a wider range of cost shocks, while the jump between $\overline{\bar{P}}_{o}$ and $\bar{P}_{o}$ becomes smaller. The increase in profit from higher renewal premiums would be bigger with a larger pool of policyholders, which is why $P_{y}$ falls as $\gamma$ rises to attract more customers in the spirit of the switching cost literature (Klemperer, 1987). However, it is important to note that $\overline{\bar{P}}_{o}$ can be inversely related to $\gamma$. This is because the profit for smaller cost shocks $\left(c_{o} \in \underline{\mathcal{C}}_{o}\right)$ has increased with higher $\gamma$, so for (9) to hold, the profit for larger cost shocks $\left(c_{o} \in \overline{\mathcal{C}}_{o}\right)$ must also go up. Since $\overline{\bar{P}}_{o}$ is too high compared to the frictionless premium near $c^{T}$, the firm lowers $\overline{\bar{P}}_{o}$ to increase profits for cost shocks near and above $c^{T}$. 

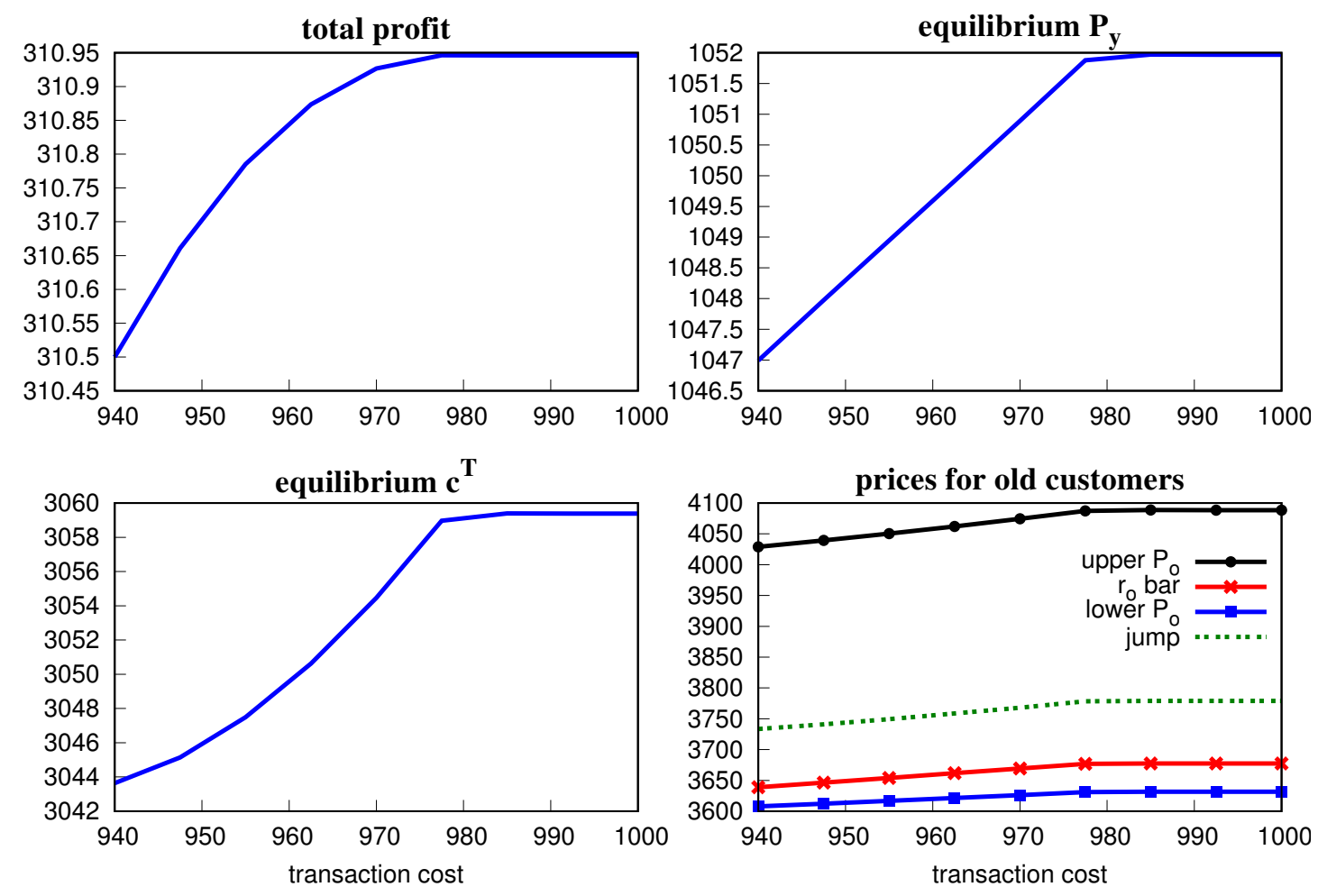

Figure 9: Varying the transaction cost $\mu$ in the model
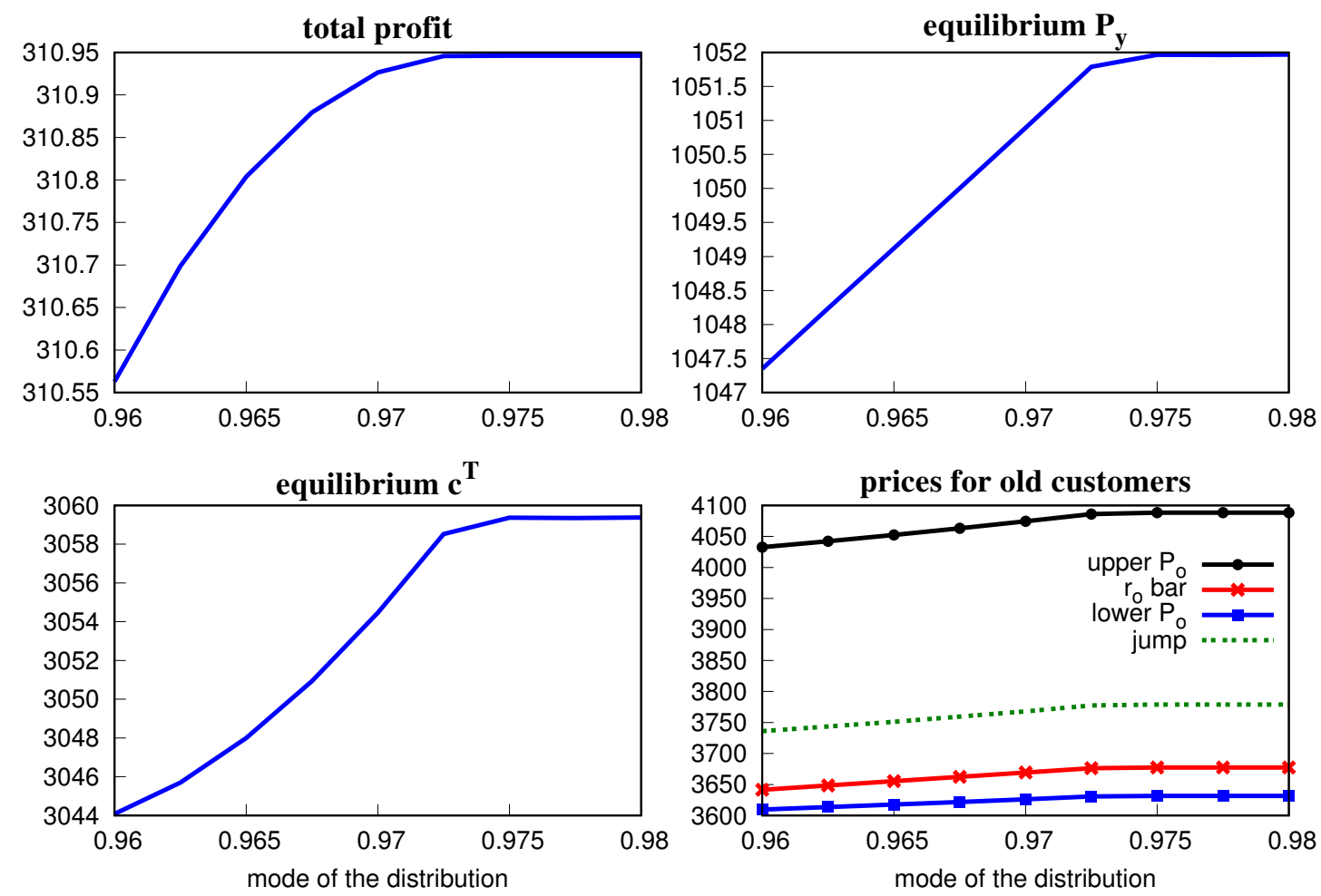

Figure 10: Varying the mode of the health shock distribution in the model 

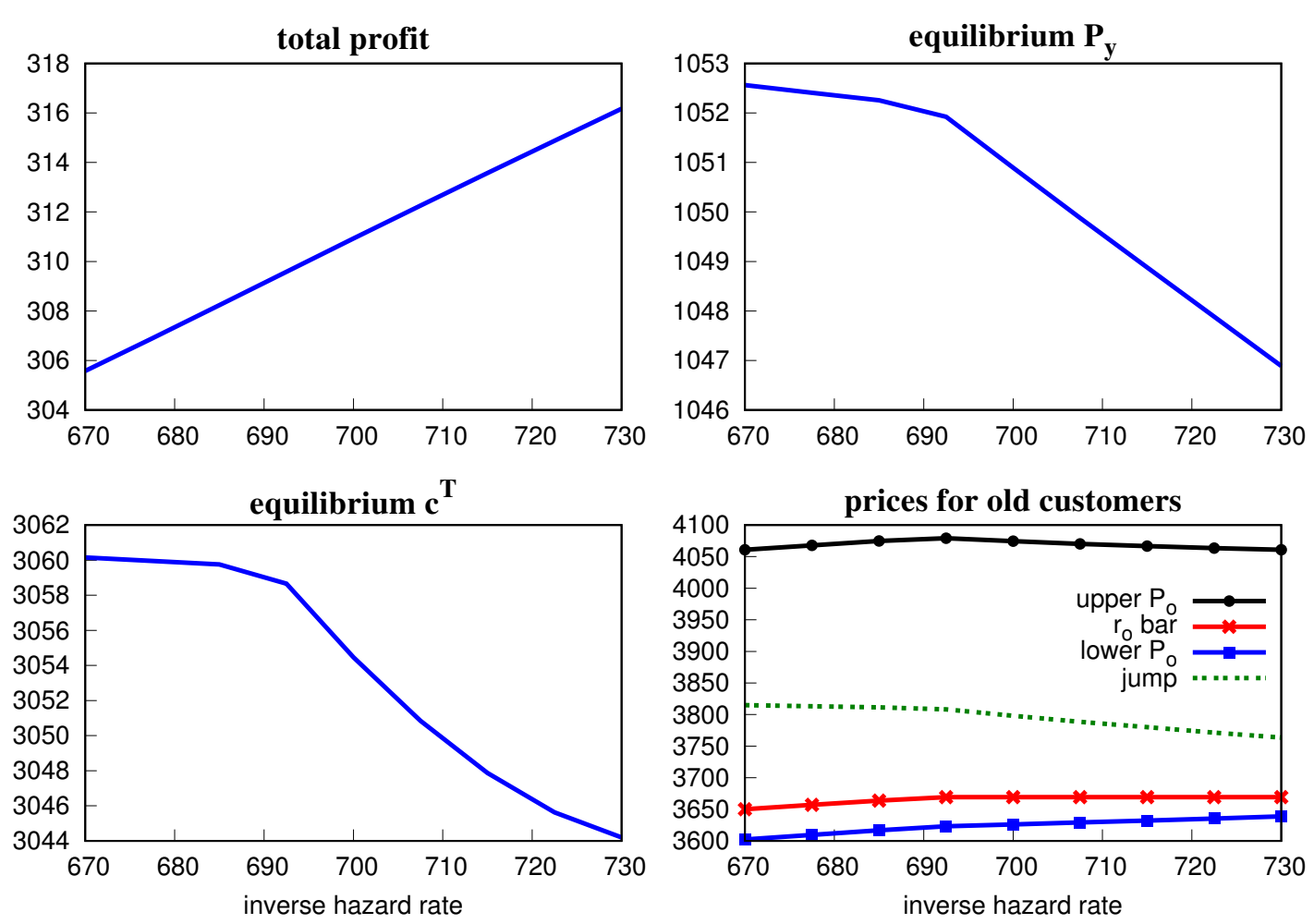

Figure 11: Varying the inverse hazard rate $\gamma$ in the model

\section{$5 \quad$ Testing the Model's Predictions}

Now we turn directly to our dataset of insurance premiums to test the main predictions of the model. In particular, as the consumer's hold-up problem becomes weaker (through a lower transaction cost $\mu$ or less adverse distribution of health shocks), the equilibrium cost thresholds $c^{T}$ and $c^{M}$ in the model fall, leading to more frequent price adjustments. At the same time, a weaker hold-up problem leads to a reduced magnitude of premium changes due to both a smaller jump between $\bar{P}_{o}$ and $\overline{\bar{P}}_{o}$, and a higher likelihood of adjustments within the frictionless pricing region. We test these predictions by looking at average probability and size of premium adjustments across time and across renewal terms. Then, we show that the marginal cost presented in Figure 5 is positively correlated with the hazard of premium adjustment, rather than size, indicating that life insurance firms tend to respond to cost shocks on the extensive margin. Finally, we contrast the price dynamics of life insurance with that of annuities, a related product but without the hold-up problem. We show that the latter change prices very frequently and by small margins. In the concluding part of this section, we use the data to address common alternative theories of price rigidity in the context of life insurance. 


\subsection{Premium Changes Across Time}

In the first test, we divide our sample into two sub-periods: 1990-1999 and 2000-2009. It can be argued that between these two time intervals, the consumer hold-up problem became weaker mainly for two reasons. First, the emergence of on-line pricing tools led to a reduced transaction cost needed to search for a life insurance policy and compare premiums across different companies and products. The internet also enabled customers to purchase policies directly from the insurance firms, avoiding the need to meet an agent physically. ${ }^{31}$ Second, mortality rates among the insured dropped significantly in the 2000s as documented by the two vintages of Select and Ultimate mortality tables issued in 2001 and 2008. For example, a cumulative 20-year probability of death for a 30-year-old male policyholder decreased from $2.36 \%$ to less than $1.96 \%$, while for a 40 -year-old male policyholder the cumulative 20-year death rate fell from $5.19 \%$ to $4.39 \%$. Analogous to a reduction in the transaction cost, a leftward shift in the distribution of health shocks in the model leads to more frequent and less sizable premium adjustments.

Table 6 presents the average fraction of premium changes and the average size of adjustments for the two sub-periods. Between the 1990s and the 2000s, the average fraction of life insurance policies adjusting premiums in any month increased from $2.31 \%$ to $2.76 \%$, while the average size of the adjustment fell from $12.02 \%$ to $10.22 \%$. Both differences are statistically significant at the $5 \%$ confidence level.

Table 6: Testing the difference in frequency and size of premium adjustments over time

\begin{tabular}{ccccc}
\hline Period & Months & \% adjusting & St. err. & p-value \\
\hline $1990-1999$ & 116 & 2.31 & 0.19 & \\
$2000-2009$ & 120 & 2.76 & 0.20 & \\
Difference & & -0.45 & 0.27 & 0.05 \\
& & & & \\
Period & Months & size (in \%) & St. err. & p-value \\
\hline 1990-1999 & 106 & 12.02 & 0.60 & \\
2000-2009 & 111 & 10.22 & 0.59 & \\
Difference & & 1.80 & 0.84 & 0.02 \\
\hline
\end{tabular}

Note: One sided t-test for equality of means, with alternative hypotheses $H_{a}: \operatorname{diff}(\%$ adjusting $)<0$ and $H_{a}: \operatorname{diff}($ size $)>0$, respectively. Average premium changes are computed only for the months where at least one is observed, hence the difference in the number of observations.

\footnotetext{
${ }^{31}$ A similar assertion is made by Brown and Goolsbee (2002) to argue that the popularization of internet pricing tools over that period of time led to an overall decrease in the level of life insurance premiums.
} 


\subsection{Premium Changes Across Renewal Terms}

In the second test, we investigate whether the frequency and size of price adjustments vary with the length of renewability term. As the term extends, the level of marginal cost, premiums, and consumers' valuations increase, while the one-time transaction cost remains unchanged (it takes the same amount nominally to invest in purchasing ART or 10-year level-term). In other words, the transaction cost falls relative to the size of the consumer's surplus as we move from one-year term to 10- and 20-year term. Suppose we calibrate our model to three different term lengths, and normalize the lower rigid price $\bar{P}_{o}$ to be equal to 100 across all calibrations. The normalized value of the transaction cost parameter $\mu$ would then decrease as the term extends. Figure 9 shows that in the model this leads to a drop in both cost thresholds, more flexibility in adjusting premiums, and a smaller jump between $\bar{P}_{o}$ and $\overline{\bar{P}}_{o}$.

Table 7 presents the frequency of premium changes, along with the average magnitude of adjustments, for the four standard lengths of level-term renewable insurance. Two stark observations arise from this test. First, as the term extends, we indeed observe a larger frequency of price changes, climbing monotonically from $1.07 \%$ for ART policies up to $3.57 \%$ for 20-year level-term. The analysis of variance between and within the groups confirms that these differences are statistically significant. Second, ART policies exhibit a significantly higher average size of the premium adjustment at 15\%, compared to roughly $10 \%$ for all the remaining term lengths. Interestingly, the term length above one year is not informative about the expected size of a premium change and the mean of squares within these three groups exceeds the means of squares between them (with p-value of the F test equal to 0.56).

Table 7: Testing the difference in frequency and size of premium adjustments across terms

\begin{tabular}{lccccc}
\hline Term length & N obs. & \% adjusting & St. err. & \multicolumn{2}{c}{ Variance analysis } \\
\hline 1 year & 13,644 & 1.07 & 0.08 & MSB & 1.69 \\
5 years & 6,537 & 2.07 & 0.18 & MSW & 0.02 \\
10 years & 20,959 & 2.99 & 0.12 & F-stat & 68.01 \\
20 years & 14,689 & 3.57 & 0.15 & p-value & 0.00 \\
& & & & & \\
Term length & N obs. & size $($ in $\%)$ & St. err. & Variance analysis \\
\hline 1 year & 146 & 15.01 & 1.00 & MSB & 1017.36 \\
5 years & 135 & 10.85 & 0.75 & MSW & 84.04 \\
10 years & 626 & 10.02 & 0.34 & F-stat & 21.11 \\
20 years & 525 & 10.38 & 0.40 & p-value & 00.00 \\
\hline
\end{tabular}




\subsection{Relationship Between Premium Changes and Cost Shocks}

We now focus on the dynamics of life insurance premiums over time using the entire available sample. Figure 12 plots the 12-month moving averages of the fraction of products that adjust their premium and the average size of the adjustment. Recall from Figure 5 that the largest shocks to marginal cost in our sample roughly occur in the late 1990s, around 2005, late 2008, and 2012. Figure 12(a) shows that each of those episodes was accompanied by an increase of at least one percentage point in the fraction of companies that adjusted their premiums, and the increase is statistically significant. On the other hand, Figure 12(b) reveals no such apparent correlation between the cost shock and the average magnitude of changes (except for late 2008, in the presence of a record-high cost). The most apparent observation from that time series is probably the gradual decline in the average size of premium jumps discussed in the previous section.

Table 8 formalizes these findings by computing correlations between the cost shock and the frequency and average size of premium changes. This relationship is generally positive for the fraction of firms that adjust and was the strongest during the 1990s, when the consumer's hold-up problem was likely to be more severe, as discussed in Section 5.1. On the other hand, the average adjustment size turns out to be negatively related to the marginal cost shock. In light of our theory, this evidence suggests therefore that life insurers respond to industrywide shocks predominantly with an increased hazard of adjusting the premiums, rather than altering the magnitude of such an adjustment.

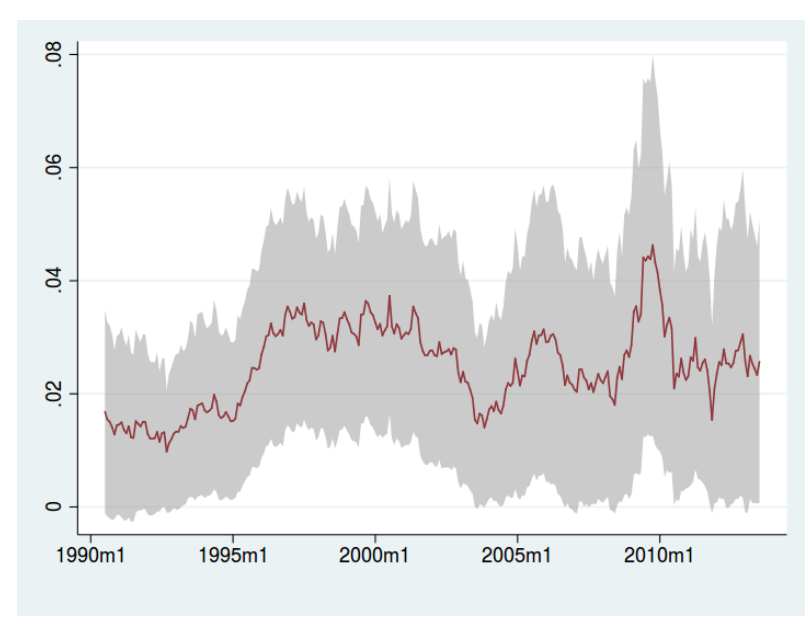

(a) Fraction of products that adjust premium

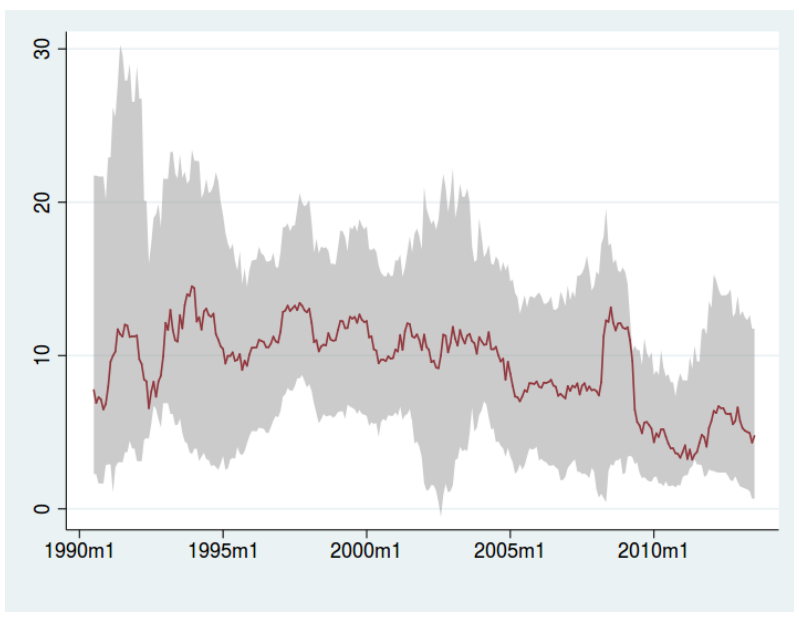

(b) Average size of premium adjustment

Note: 6-month moving averages applied. Gray areas depict the $95 \%$ confidence intervals.

Figure 12: Fraction and average size of premium changes 
Table 8: Correlation between the cost shock and frequency/size of premium changes

\begin{tabular}{lcc}
\hline Correlation with cost: & \% adjusting & adjustment size \\
\hline $1990-1999$ & 0.67 & 0.24 \\
$2000-2009$ & 0.20 & -0.03 \\
Full sample & 0.28 & -0.18 \\
\hline
\end{tabular}

\subsection{Comparison with Annuities}

So far we have demonstrated that renewable life insurance premiums are rigid, adjust by large margins and these properties tend to diminish as the hold-up problem gets weaker. It is then instructive to contrast these findings against the price dynamics of a related product that is free of the hold-up altogether. A good example of such a product is annuity, typically offered by the same life insurance companies, where consumers pay a single lump-sump amount up front in exchange for a schedule of fixed benefits until death. Depending on policy, these benefits may carry a 10- or 20-year guarantee in case the insured dies earlier.

Table 9: Price changes in life annuities vs. life insurance: Jan 2007 - Jul 2009

\begin{tabular}{lrr}
\hline & Life annuities & Life insurance \\
\cline { 2 - 3 } Number of observations & 8140 & 4266 \\
Number of firms & 19 & 76 \\
Number of products & 304 & 147 \\
\hline Probability of price change (in \%): & & \\
Average (weighted) & 71.5 & 2.6 \\
Average (unweighted) across firms & 68.9 & 2.6 \\
Median (unweighted) across firms & 74.2 & 0 \\
\hline Distribution of change sizes (in \%): & & \\
Average & 1.85 & 9.34 \\
Median & 1.50 & 6.67 \\
Standard deviation & 1.55 & 9.18 \\
\hline
\end{tabular}

Note: the data is acquired from Koijen and Yogo (2015) and originally comes from the WebAnnuities Insurance Agency.

We use the annuity prices collected and made available by Koijen and Yogo (2015). This data was originally provided by the WebAnnuities Insurance Agency and comes at monthly frequency from January 2007 to August 2009. ${ }^{32}$ The quotes are available for males and females at all ages from 50 to 85 (in five year intervals). Table 9 presents the price rigidity in life annuities. Intriguingly, prices change in any given month with around $70 \%$ probability,

\footnotetext{
${ }^{32}$ The full dataset is semi-annual and covers the years from 1989 until 2011. However, the panel is highly unbalanced, making it difficult to make a compelling case on price rigidity.
} 
and the magnitude of those adjustments is small, around 1.5\%. A natural concern then may be that this price dynamics is a result of the financial crisis in years 2007-2009. For this reason, in the right-hand side column we also provide information about premium rigidity from our own sample, adapted to the time period of interest. The premiums during the financial crisis were as rigid as in the entire sample described in Table 2, while the adjustment sizes are slightly smaller, consistent with the evidence presented in Section 5.1.

\subsection{Alternative theories}

We now investigate whether the rigidity of life insurance premiums could potentially be explained by existing models of price stickiness. Following Klenow and Kryvtsov (2008), we consider two broad classes of models: time-dependent and state-dependent pricing models. Then, we investigate if a model of competition can generate realistic premium rigidity.

\subsubsection{Time-Dependent Models of Sticky Prices}

In time-dependent pricing frameworks, for example Taylor (1980) or Calvo (1983), firms adjust prices with exogenous frequency. The spell duration is subject to a random shock and every period a fixed number of firms reoptimize their price. The longer an individual price remains staggered, the more shocks accumulate in the meantime, resulting in larger average size of the adjustment. In a time-dependent pricing setup, we would expect to observe variation on the intensive margin, and much less so on the extensive margin which is determined exogenously. Figure 12 shows that the opposite appears to be the case in the life insurance market, where the firms tend to respond to cost shock predominantly on the extensive margin. In addition, Figure 13 shows a plot of all premium changes in our data (expressed in absolute value) as function of premium duration. As can be noticed, the points are scattered with no clear pattern and the correlation of the two variables is about 0.13. Table 10 confirms this in a regression analysis. The relationship between premium duration and size of the adjustment is rather weak (albeit positive), with the slope of $0.07 \%$ and R-squared of less than 0.02. We conclude that the standard time-dependent models are not a promising alternative to explain premium rigidities observed in the life insurance market.

Table 10: Regression results (dependent variable: abs_change)

\begin{tabular}{lcccrl}
\hline & coefficient & s.e. & $P>|z|$ & & \\
\cline { 2 - 4 } constant & 9.372 & 0.372 & 0.000 & No. of obs. & 1432 \\
duration & 0.066 & 0.014 & 0.000 & Adj. R-sq. & 0.016 \\
\hline
\end{tabular}




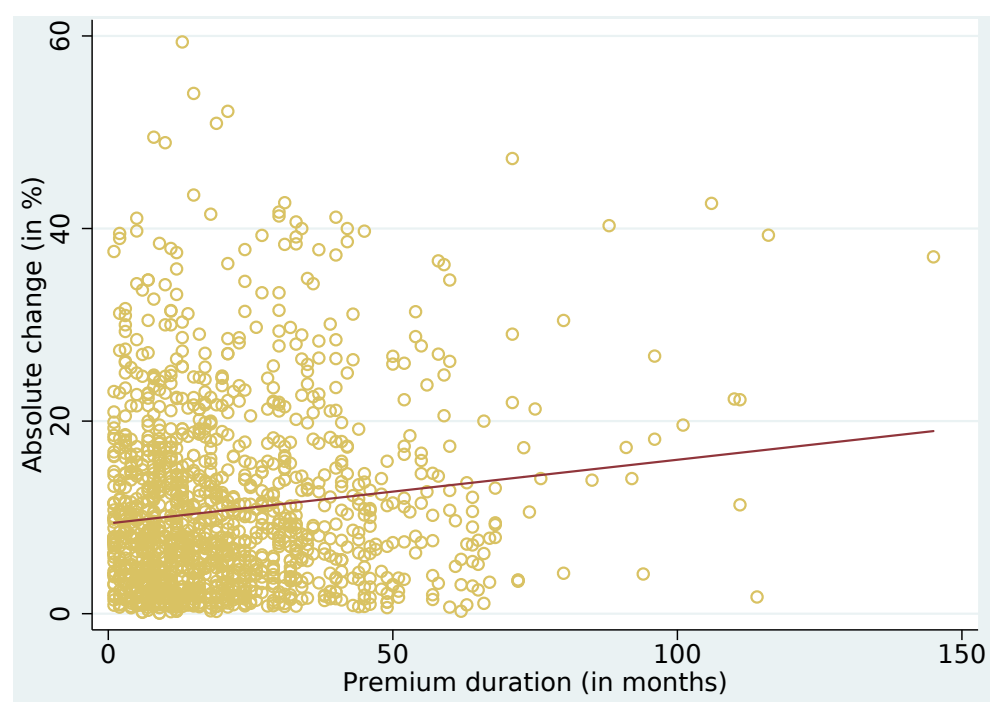

Figure 13: Premium duration and adjustment size in the life insurance market

\subsubsection{State-Dependent Models of Sticky Prices}

By contrast, in state-dependent pricing models, for example Dotsey et al. (1999) or Golosov and Lucas (2007), individual firms are subject to heterogeneous "menu costs" and can choose when to adjust their prices. Changes then occur predominantly on the extensive margin, and the hazard of price change is an increasing function of duration because incoming shocks move the optimal price away from the one currently posted. Figure 14 plots the hazard of premium adjustment in our dataset at all durations for which we observe multiple changes. Notice that the relationship is generally negative, with the correlation of -0.44 . Table 11 summarizes the regression results of change hazard on duration. An additional month of premium duration tends to reduce the hazard by $0.01 \%$, but only $18 \%$ of the variation in hazard can be explained through this channel. Interestingly, it appears that the increasing hazard may be a local feature of the premiums that have remained staggered for more than 50 months. We do not have enough observations to make this assertion robust though. We conclude that state-dependent pricing theories are not readily capable of explaining premium rigidity in the life insurance market.

Table 11: Regression results (dependent variable: hazard)

\begin{tabular}{lrrrrl}
\hline & coefficient & s.e. & $P>|z|$ & & \\
\cline { 2 - 4 } constant & 0.0309 & 0.00176 & 0.000 & No. of obs. & 88 \\
duration & -0.0001 & 0.00003 & 0.000 & Adj. R-sq. & 0.184 \\
\hline
\end{tabular}




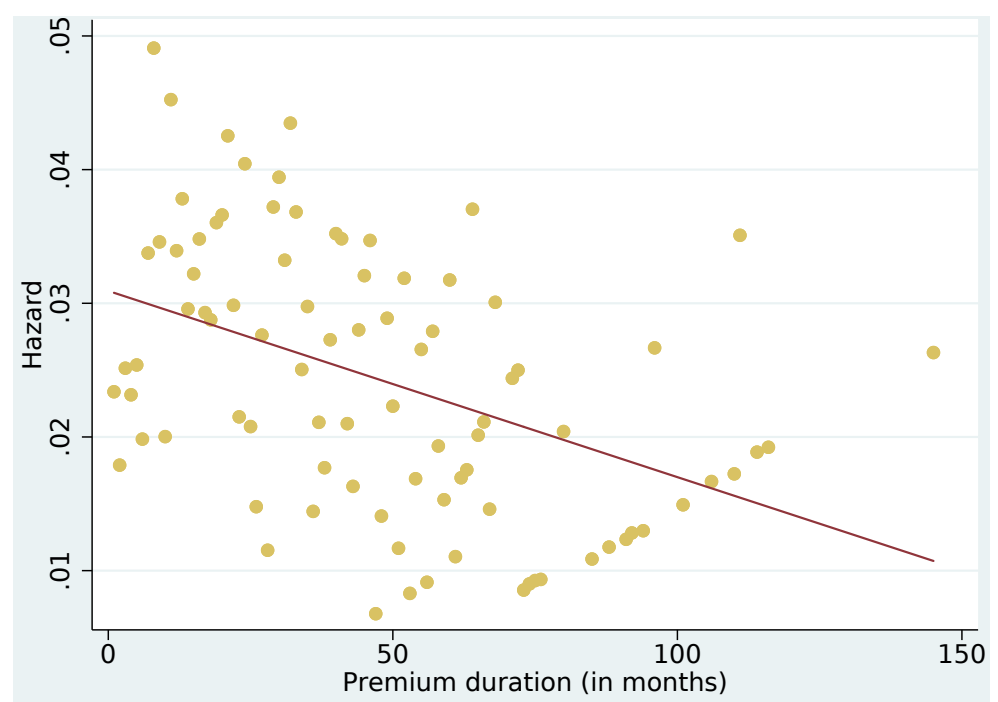

Figure 14: Premium duration and adjustment hazard in the life insurance market

On a more general level, menu costs do not appear to be an appealing explanation for price rigidity in markets, such as life insurance, where prices are posted electronically and setting them is a core business activity. For example, in Section 5.4 we show that annuities prices tend to adjust very frequently and by small margin, contradicting a hypothesis that menu costs play an important role in such products.

\subsubsection{Competition}

Our model accounts for market competition in a reduced form, allowing consumers to search for an outside option in the renewable insurance market. It has been shown in the literature though that explicit modeling of competition can also generate price rigidity. In a monopolistically competitive market, Nishimura (1986) shows that prices become rigid as the price elasticity of demand approaches infinity if a firm cannot infer whether a transient cost shock is market-wide or firm-specific. Firms set prices based on the expectation of other firms' prices. If a firm responds to the cost shock by increasing its price then, with elastic demand, it will attract few consumers when the shock is firm-specific. On the other hand, if a firm responds to the cost shock by lowering its price, then it would attract many consumers when the shock is firm-specific, but the lower price is not profitable. As a result, equilibrium prices become less sensitive to transient shocks as markets become more competitive.

Even though competition can generate price rigidity in an incomplete information environment, it also entails price concentration. Indeed, if prices were dispersed, then firms with high prices would not be competitive. However, the dispersion in life insurance premiums (measured by the coefficient of variation) is generally high suggesting that life insurance 
markets are not competitive. Table 12 summarizes the premium dispersion for our four standard term lengths. The dispersion decreases with term length, with an exception for the 20-year level-term which also has a much higher standard deviation so its premiums may not be statistically more dispersed than shorter-term contracts. From Table 7, premiums adjust more frequently as the term length increases. This suggests that the relationship between price dispersion and rigidity runs counter to the prediction of Nishimura (1986).

Table 12: Coefficient of variation of premiums across terms

\begin{tabular}{llcll}
\hline Term length & Mean & St. dev. & Min. & Max. \\
\hline 1 year & 0.18 & 0.02 & 0.15 & 0.23 \\
5 years & 0.17 & 0.03 & 0.11 & 0.28 \\
10 years & 0.15 & 0.03 & 0.11 & 0.21 \\
20 years & 0.17 & 0.05 & 0.06 & 0.28 \\
\hline
\end{tabular}

Note: For each term length, this table shows the distribution of cross-sectional coefficients of variation over time. The total number of observations is 282 months.

\section{Conclusion}

We show that the market for life insurance has exhibited a remarkable degree of price rigidity since 1990. Firms that changed premiums in the analyzed sample did so on average every 39 months, preferring one-time jumps of large magnitude to more frequent and gradual price adjustments. We build a theoretical model to explain this phenomenon, based on the assumption that consumers are locked-in due to a relationship-specific investment. In line with what we find in the data, the model predicts that premiums remain constant for a wide range of cost shock realizations, while potential changes take the form of discrete jumps.

Our hypothesis is obviously not the only explanation for the observed rigidity of life insurance premiums. As Table 7 shows, even the 20-year level-term premiums are quite rigid which leaves room for complementary theories. At the same time however, we provide guidelines for future research by showing that life insurance data does not support the standard price stickiness models.

The broader implications of our work include providing microfoundations for price stickiness observed in the markets characterized by long-term commitment. In particular, we show that the price rigidity arises endogenously as a solution to a time inconsistency problem that could otherwise deter consumers from buying the good. Future research should investigate the pricing behavior of other financial or contractual services, and find out if similar products also exhibit pricing anomalies such as the ones found in life insurance contracts. 


\section{References}

Alonso, Ricardo and Niko Matouschek, "Relational Delegation," RAND Journal of Economics, 2007, 38 (4), 1070-1089.

_ and _, "Optimal Delegation," Review of Economic Studies, 2008, 75, 259-293.

Amador, Manuel and Kyle Bagwell, "The Theory of Optimal Delegation with an Application to Tariff Caps," Econometrica, 2013, 81 (4), 1541-1599.

_, Ivan Werning, and George-Marios Angeletos, "Commitment vs. Flexibility," Econometrica, 2006, 74 (2), 365-396.

Bils, Mark and Peter J. Klenow, "Some Evidence on the Importance of Sticky Prices," Journal of Political Economy, 2004, 112 (5).

Brown, Jeffrey R. and Austan Goolsbee, "Does the Internet Make Markets More Competitive? Evidence from the Life Insurance Industry," Journal of Political Economy, 2002, $110(3), 481-507$.

California Department of Insurance, "California Life \& Annuity Insurance Industry: 2003 Market Share Report," Rate Specialist Bureau, Department of Insurance, 2004.

Calvo, Guillermo A., "Staggered Prices in a Utility-Maximizing Framework," Journal of Monetary Economics, 1983, 12 (3).

Cawley, John and Tomas Philipson, "An Empirical Examination of Information Barriers to Trade in Insurance," American Economic Review, 1999, 89 (4).

Cullen, Joseph and Oleksandr Shcherbakov, "Measuring consumer switching costs in the wireless industry," Unpublished manuscript, 2010.

Daily, Glenn, Igal Hendel, and Alessandro Lizzeri, "Does the Secondary Life Insurance Market Threaten Dynamic Insurance?," American Economic Review, Papers and Proceedings, 2008, 98 (2).

Dotsey, Michael, Robert King, and Alexander Wolman, "State-Dependent Pricing and the General Equilibrium Dynamics of Money and Output," Quarterly Journal of Economics, 1999, 114 (2).

Fang, Hanming and Edward Kung, "Why Do Life Insurance Policyholders Lapse? The Roles of Income, Health and Bequest Motive Shocks," Working Paper, 2012. 
_ and _, "Life Insurance and Life Settlements: The Case for Health-Contingent Cash Surrender Values," Journal of Risk and Insurance, 2018.

- and Zenan Wu, "Life Insurance and Life Settlement Markets with Overconfident Policyholders," Working Paper, 2019.

Ge, Shan, "Internal Capital Markets and Product Pricing: Evidence from Weather and Life Insurance Premiums," Working Paper, 2019.

Golosov, Mikhail and Robert E. Lucas, "Menu Costs and Phillips Curves," Journal of Political Economy, 2007, 115 (2).

Gottlieb, Daniel, "Prospect Theory, Life Insurance, and Annuities," Working Paper, 2018.

- and Kent Smetters, "Lapse-Based Insurance," Working Paper, 2016.

Gurkaynak, Refet S., Brian Sack, and Jonathan H. Wright, "The U.S. Treasury Yield Curve: 1961 to the Present," Journal of Monetary Economics, 2007, 54 (8).

Halac, Marina and Pierre Yared, "Fiscal Rules and Discretion Under Persistent Shocks," Econometrica, 2014, 82 (5).

_ and _ , "Fiscal Rules and Discretion under Limited Enforcement," Working Paper, 2019.

Handel, Benjamin R., "Adverse Selection and Inertia in Health Insurance Markets: When Nudging Hurts," American Economic Review, 2013, 103 (7).

Hendel, Igal and Alessandro Lizzeri, "The Role of Commitment in Dynamic Contracts: Evidence from Life Insurance," Quarterly Journal of Economics, 2003, 118 (1).

Holmstrom, Bengt, "On the Theory of Delegation," in Marcel Boyer and Richard Kihlstrom, eds., Bayesian Models in Economic Theory, New York: North Holland, 1984.

Honka, Elisabeth, "Quantifying search and switching costs in the US auto insurance industry," The RAND Journal of Economics, 2014, 45 (4).

Hortacsu, Ali and Chad Syverson, "Product Differentiation, Search Costs, and Competition in the Mutual Fund Industry: A Case Study of S\&P 500 Index Funds," Quarterly Journal of Economics, 2004, 119.

Huntington, Henry S., "Derivation of Premium Rates for Renewable Term Insurance," Transactions of Society of Actuaries, 1958, 10 (28). 
Illanes, Gastón, "Switching Costs in Pension Plan Choice," Unpublished manuscript, 2016.

Klemperer, Paul, "Markets with Consumer Switching Costs," Quarterly Journal of Economics, 1987, 102 (2).

Klenow, Peter J. and Oleksiy Kryvtsov, "State-Dependent or Time-Dependent Pricing: Does it Matter for Recent U.S. Inflation," Quarterly Journal of Economics, 2008, 123 (3).

Koijen, Ralph S. J. and Motohiro Yogo, "The Cost of Financial Frictions for Life Insurers," American Economic Review, 2015, 105 (1).

LIMRA, "What's happening in the term marketplace," LIMRA's MarketFacts, 1994, 13 (2).

Melumad, Nehum and Toshiyuki Shibano, "Communication in Settings with No Transfers," RAND Journal of Economics, 1991, 22 (2).

Miller, Daniel P. and Jungwon Yeo, "Estimating Switching Costs with Market Share Data: An Application to Medicare Part D," International Journal of Industrial Organization, 2018, 61 .

Nakamura, Emi and Jon Steinsson, "Price Setting in Forward-Looking Customer Markets," Journal of Monetary Economics, 2011, 58.

Nishimura, Kiyohiko, "Rational Expectations and Price Rigidity in a Monopolistically Competitive Market," Review of Economic Studies, 1986, 53.

Nosal, Kathleen, "Estimating Switching Costs for Medicare Advantage Plans," Unpublished manuscript, 2012.

Pauly, Mark, Kate Withers, Krupa Subramanian-Viswanathan, Jean Lemaire, John Hershey, Katrina Armstrong, and David Asch, "Price Elasticity of Demand for Term Life Insurance and Adverse Selection," NBER Working Paper, 2003, 9925.

Shcherbakov, Oleksandr, "Measuring consumer switching costs in the television industry," The RAND Journal of Economics, 2016, 47 (2).

Taylor, John B., "Aggregate Dynamics and Staggered Contracts," Journal of Political Economy, 1980, 88 (1).

Weiergräber, Stefan, "Network Effects and Switching Costs in the US Wireless Industry. Disentangling Sources of Consumer Inertia," SFB/TR 15 Discussion Paper, 2014, 512. 


\section{Appendices (for online publication)}

\section{A Measurement Error}

As we discuss in Section 2.2, we approximate the life insurance companies' adherence to nonbinding "current" premiums by measuring the premium rigidity for a fixed set of customer characteristics. This is a reasonable assumption as long as firms tend to adjust the entire age schedules at the same time and with the same frequency. In this section, we test whether this is the case by comparing premiums for two separate age groups.

In addition to the baseline profile of 30-year-old male, we also extracted premiums for 10-year level-term policies for a fixed profile of 40-year-old male of the same health category. The main goal of obtaining this data was to validate the predictions of our quantitative model about renewal premiums in Section 4.1.2. Here, we can use the same dataset to check whether companies in fact tend to adjust premiums for 30- and 40-year-olds with the same frequency and at the same time.

Table 13 presents the number of premium changes observed for the two age groups. Altogether, there are 16 extra instances of premium adjustments for 40-year-olds relative to 30-year-olds, a difference smaller than 3\%. This confirms our measurement assumption in Section 2.1 that premium rigidity for a fixed set of customer characteristics implies the companies' adherence to the "Non-guaranteed current" premiums in Table 1.

Table 13: Number of premium changes in 10-year level-term policies: 30- vs. 40-year-olds

\begin{tabular}{llc}
\hline Customer age & N obs. & N changes \\
\hline 30 & 20,815 & 623 \\
40 & 20,815 & 639 \\
\hline
\end{tabular}

Note: We analyze matched product-month observations from the two datasets. Because of occasional inconsistencies in Compulife, there are fewer resulting observations here than if we were to consider premiums in isolation for 30-year-olds (as in Table 7) or for 40-year-olds (as in Table 5).

The final question to ask is whether the changes in 30-year-old and 40-year-old premiums in fact coincide in time. The first row of Table 14 shows that this is the case exactly in 566 cases, while there are 57 and 73 incidences where a premium change occurs only for a 30year-old and a 40-year-old customer, respectively. In such cases though, we often observe that changes to premiums for different ages are separated from each other by up to three months, indicating a possible reporting error in Compulife, or a gradual implementation of an adjustment to the whole age schedule. Subsequent rows of Table 14 reveal that close to 
half of the premium changes that do not coincide in time are in fact only separated from each other by up to three months.

Table 14: Coincidence of premium changes in 10-year level-term policies: 30 - vs. 40-year-olds

\begin{tabular}{|c|c|c|c|}
\hline Tolerance & Only 30 & Both & Only 40 \\
\hline same month & 57 & 566 & 73 \\
\hline \pm one month & 49 & 584 & 57 \\
\hline \pm two months & 28 & 592 & 52 \\
\hline \pm three months & 25 & 599 & 50 \\
\hline
\end{tabular}

Note: Same remarks apply as in Table 13. A change in premium is here assumed to coincide with the tolerance of zero, one, two and three months, correspondingly.

\section{B Nominal and Real Rigidity}

This section analyzes the effect of inflation on life insurance premiums. We first show that nominal rigidity implies real rigidity per dollar of real face value, and vice versa. Next, we discuss how inflation affects the pricing behavior of life insurers and how it relates to the results of our paper.

Consider a simple framework where perfectly competitive life insurance companies face a constant mortality rate $m$ and a constant interest rate $r$, The (nominal) face value of a generic policy is $F_{t}$, and its real counterpart is $F_{t}^{R}$, where $t=0$ is the base year. Let $P_{t}^{N}$ denote the nominal premium for a one-period (non-renewable) insurance and $P_{t}^{R}$ be the real premium. Let $\pi$ be a (constant) inflation rate. Then, Lemma 4 shows that nominal premiums are rigid if and only if real premiums per dollar of real face value are rigid.

Lemma 4 For any $t, P_{t}^{N}=P^{N}$ if and only if for all $t, \frac{P_{t}^{R}}{F_{t}^{R}}=\bar{P}^{R}$.

Proof To show sufficiency, suppose that in a competitive market for non-renewable insurance, nominal premiums are rigid (i.e. the mortality rate, interest rate and nominal face value are fixed): for all $t$,

$$
P_{t}^{N}=\frac{m}{1+r} F_{t}=\frac{m}{1+r} F .
$$


The real premium is given by

$$
\begin{aligned}
P_{t}^{R} & =\frac{P^{N}}{(1+\pi)^{t}} \\
& =\frac{m}{1+r} \frac{F}{(1+\pi)^{t}} \\
& =\frac{m}{1+r} F_{t}^{R} .
\end{aligned}
$$

The real premium per dollar of real face value is

$$
\frac{P_{t}^{R}}{F_{t}^{R}} F_{0}=\frac{m}{1+r} F_{0} \equiv \bar{P}^{R},
$$

where $F_{0}$ is the face value in the base year. This shows that nominal rigidity of premiums implies that premiums are also rigid for a policy with fixed real face value.

The proof for necessity follows exactly the steps shown above in the reverse order.

From the proof of Lemma 4, notice that as the nominal premium is rigid by assumption, the real premium decreases over time at the constant rate of inflation $\pi$. However, this is not the insurance product that we consider in our model, because its real face value also decreases over time. Our model assumes a constant real face value, so the focus of Lemma 4 is on the real premium per dollar of real face value.

Now, consider a two-period renewable insurance policy. Let $P_{t, a}^{N}$ denote the nominal premium in period $t$ dollars for age $a$ individual, and let $P_{t, a}^{R}$ be the real premium. The nominal payment over time is $\left(P_{t, a}^{N}, P_{t+1, a+1}^{N}\right)$. The next lemma uses Lemma 4 to establish the equivalence relation between nominal and real rigidity in a competitive market for renewable insurance. The result can be generalized to any $n$-period renewable insurance.

Lemma 5 For any $t$ and age $a, P_{t, a}^{N}=P_{a}^{N}$ if and only if for any $t$ and any age $a, \frac{P_{t, a}^{R}}{F_{t}^{R}}=\bar{P}_{a}^{R}$.

Proof To prove sufficiency, we define the actuarially fair premiums for renewable insurance according to the backward induction approach of Huntington (1958) (for details, see Appendix $\mathrm{C}$ ). In $t+1$, a policy bought in $t$ at age $a$, becomes non-renewable and the actuarially fair premium satisfies $P_{t+1, a+1}^{N}=\frac{m}{1+r} F$. In $t$, nominal premiums satisfy a zero-profit condition

$$
P_{t, a}^{N}+\frac{1-m}{1+r} P_{t+1, a+1}^{N}=F\left[\frac{m}{1+r}+\frac{m(1-m)}{(1+r)^{2}}\right]
$$


Converting nominal premiums to real ones yields

$$
\begin{aligned}
& P_{t, a}^{R}(1+\pi)^{t}+\frac{1-m}{1+r} P_{t+1, a+1}^{R}(1+\pi)^{t+1}=F\left[\frac{m}{1+r}+\frac{m(1-m)}{(1+r)^{2}}\right] \\
& \Longleftrightarrow \frac{P_{t, a}^{R}}{F_{t}^{R}} F+\frac{1-m}{1+r} \frac{P_{t+1, a+1}^{R}}{F_{t+1}^{R}} F=F\left[\frac{m}{1+r}+\frac{m(1-m)}{(1+r)^{2}}\right] .
\end{aligned}
$$

The second lines follows from the fact that $F_{t}^{R}=\frac{F_{0}}{(1+\pi)^{t}}$ and $F_{0}=F$, since $t=0$ is the base year. By Lemma $4, P_{t+1, a+1}^{N}=P_{a+1}^{N}$ if and only if $\frac{P_{t+1, a+1}^{R}}{F_{t}^{R}}=\bar{P}_{a+1}^{R}$ for any $t$ and $a$. As a result, if for all $t$ and $a, P_{t, a}^{N}=P_{a}^{N}$ and $P_{t+1, a+1}^{N}=P_{a}^{N}$, it immediately follows that $\frac{P_{t, a}^{R}}{F_{t}^{R}}=\bar{P}_{a}^{R}$.

The proof for necessity follows exactly the steps above in the reverse order.

Lemmas 4 and 5 show that the nominal rigidity observed in the data is equivalent to real rigidity per dollar of real face value in the simplest case of actuarially fair premiums. As inflation erodes the value of premiums paid by consumers over time, it does so with the value of death benefits as well. From this point of view, a theory of real price rigidity (such as the one presented in this paper) is informative for explaining the nominal rigidity observed in the data.

Naturally, the presence of inflation may affect the pricing strategy of insurers by inducing them to change the age profile of premiums. As pointed out by Hendel and Lizzeri (2003), life insurance premiums are typically front-loaded which implies that the majority of the profit comes from initial premiums. For example, an increase in expected inflation may lead to more front-loading and higher profit because the nominal value of death benefits will be eroded more than the value of premiums. This suggests that a model in real terms may not capture the full dynamics of front-loaded nominal premiums. In other words, in a world without inflation we would expect premiums to be even more rigid than what we already observe in the data and document in Section 2. Therefore, a theory of real premium rigidity is needed to explain these facts. 


\section{Estimating the Marginal Cost of Life Insurance}

In what follows, let $m_{t, n, \bar{n}}$ denote the period $t$ mortality rate of age $n$ individuals who bought life insurance at age $\bar{n},{ }^{33}$ and let $N$ be the maximum attainable age according to the corresponding mortality tables. Let $R_{t}(i)$ be the (annualized) interest rate on zero-coupon risk-free securities with maturity $i$ at time $t$. The schedule of actuarially fair values for an ART policy acquired at age $n$ for ages up to $N$ per dollar of death benefit is defined as $\left\{P_{t}(i)\right\}_{i=n, n+1, \ldots, N}$ and obtained by solving the following equation

$$
\sum_{i=1}^{N-s} \frac{\prod_{j=0}^{i-2}\left(1-m_{t, s+j, n}\right) m_{t, s+i-1, n}}{R_{t}^{i}(i)}=P_{t}(s)+\sum_{i=1}^{N-s-1} \frac{\prod_{j=0}^{i-1}\left(1-m_{t, s+j, n}\right) P_{t}(s+i)}{R_{t}^{i}(i)}
$$

recursively for every age $s=N-1, N-2, \ldots, n$. Following the method presented by Huntington (1958), we calculate the full schedule of actuarially fair values backwards, starting from the highest admissible age. Formula (11) can further be augmented to account for two additional features of renewable term policies. First, at certain age $N_{c}<N$ the consumer may choose to convert to a universal life insurance and pay a fixed premium for all the remaining periods up to $N$. Second, the premium may be renewed at frequencies lower than one year, in particular in 5-, 10- or 20-year intervals. ${ }^{34}$

Notice that formula (11) does not take into account potential lapsation of policies, that is the possibility that a consumer may choose not to renew it. This is because there is currently no industry-wide standard for insurance pricing with lapsation, and data lapsation is scarce and varies widely across different policies and time. Similarly as in Koijen and Yogo (2015), for simplicity we ignore lapsation in our analysis.

In our calculation of the actuarially fair value we use the mortality tables issued by the American Society of Actuaries. We apply the 1980 Commissioners Standard Ordinary (CSO) table for all years prior to January 2001, the 2001 Valuation Basic Table (VBT) prior to January 2008 and the 2008 VBT for the time period following January 2008. We use geometric averaging on the monthly basis to smooth the transition between any two vintages of the mortality tables. It is important to emphasize that these tables are created based on the actual mortality rates among the insured rather than the general population. For this reason, they account for a potential adverse selection in the market for life insurance. ${ }^{35}$ For the risk-free interest rate we use the U.S. Treasury zero-coupon yield curve. ${ }^{36}$

\footnotetext{
${ }^{33}$ It is important to keep track of different cohorts of the insured due to adverse selection, i.e. individuals who have already held a policy tend to have significantly higher mortality rates than the same-age newcomers.

${ }^{34}$ To estimate the cost in Figure 5 we use a one-year level term policy with $N=60$ and no convertibility.

${ }^{35}$ Cawley and Philipson (1999) found no strong evidence of adverse selection in the term life insurance.

${ }^{36}$ Taken from Gurkaynak et al. (2007) and averaged for each month.
} 


\section{Proofs}

Proof of Lemma 1: First note that $B^{r e n}\left(r_{o} ; t\right) \geq B^{\text {non }}\left(r_{o} ; t\right)$ and $B^{r e n}\left(r_{o} ; t\right), B^{\text {non }}\left(r_{o} ; t\right) \geq$ 0 for all $r_{o}$ and for all $t$. This is because there are more options available for renewable policyholders and consumers can always choose to forgo coverage.

Next, we show that $B^{\text {non }}\left(r_{o} ; t\right)$ and $B^{r e n}\left(r_{o} ; t\right)$ are weakly increasing in $r_{o}$ for any $t$. Note that there exists $\tilde{r}_{o}$ such that for all $r_{o}<\tilde{r}_{o}, B^{n o n}\left(r_{o} ; t\right)=0$ and for $r_{o} \geq \tilde{r}_{o}$, we have

$$
\begin{aligned}
B^{\text {non }}\left(r_{o} ; t\right) & =\int_{\underline{c}}^{\bar{c}}\left[\int_{\epsilon} \max \left\{0, r_{o}-\epsilon c_{o, t+1}\right\} d Z(\epsilon)-\mu\right] d G\left(c_{o, t+1}\right) \\
& =\int_{\underline{c}}^{\bar{c}} \int_{0}^{\frac{r_{o}}{c_{o, t+1}}}\left(r_{o}-\epsilon c_{o, t+1}\right) g\left(c_{o, t+1}\right) z(\epsilon) d \epsilon d c_{o, t+1}-\mu .
\end{aligned}
$$

Differentiating $B^{\text {non }}\left(r_{o} ; t\right)$ with respect to $r_{o}$ yields $\int_{\underline{c}}^{\bar{c}} Z\left(\frac{r_{o}}{c_{o, t+1}}\right) d G\left(c_{o, t+1}\right)$, so $B^{\text {non }}\left(r_{o} ; t\right)$ is strictly increasing for $r_{o} \geq \tilde{r}_{o}$. Since $B^{r e n}\left(r_{o} ; t\right) \geq B^{\text {non }}\left(r_{o} ; t\right), B^{r e n}\left(r_{o} ; t\right)$ is also strictly increasing for $r_{o} \geq \tilde{r}_{o}$.

Suppose there exists valuation $\hat{r}_{o}$ such that $B^{r e n}\left(\hat{r}_{o} ; t\right)>B^{n o n}\left(\hat{r}_{o} ; t\right)$. We will show that $B^{r e n}\left(r_{o} ; t\right)-B^{\text {non }}\left(r_{o} ; t\right)$ is increasing in $r_{o} \geq \hat{r}_{o}$. If $B^{r e n}\left(\hat{r}_{o} ; t\right)>B^{\text {non }}\left(\hat{r}_{o} ; t\right)$, then there exists a set $\hat{\mathcal{C}}$ with strictly positive measure defined as $\hat{\mathcal{C}}=\left\{c_{o, t+1} \mid \hat{r}_{o}>P_{o, t+1}\left(c_{o, t+1}\right)\right\}$. Since if $\hat{\mathcal{C}}$ is empty or measure zero, then it cannot be the case that $B^{r e n}\left(\hat{r}_{o} ; t\right)>B^{\text {non }}\left(\hat{r}_{o} ; t\right)$. For $r_{o} \geq \hat{r}_{o}$, we have

$$
\begin{aligned}
& B^{\text {ren }}\left(r_{o} ; t\right)-B^{\text {non }}\left(r_{o} ; t\right) \geq \\
& \int_{\hat{\mathcal{C}}} \max \left\{r_{o}-P_{o, t+1}\left(c_{o, t+1}\right), \int_{\epsilon} \max \left\{r_{o}-P_{o, t+1}\left(c_{o, t+1}\right), r_{o}-\epsilon c_{o, t+1}\right\} d Z(\epsilon)-\mu\right\} d G\left(c_{o, t+1}\right) \\
& \quad-\int_{\hat{\mathcal{C}}}\left[\int_{\epsilon} \max \left\{0, r_{o}-\epsilon c_{o, t+1}\right\} d Z(\epsilon)-\mu\right] d G\left(c_{o, t+1}\right) . \quad(12)
\end{aligned}
$$

The inequality comes from the fact that for higher valuations the set of costs such that $r_{o}>P_{o, t+1}\left(c_{o, t+1}\right)$ should be weakly larger. Let $\hat{C}^{r}$ denote the set of cost realizations where the policyholder would renew immediately and $\hat{C}^{s}$ denote the set where the policyholders search. Define the two sets such that they are mutually exclusive (if policyholders are 
indifferent, they renew), then the right-hand side of (12) can be rewritten as

$$
\begin{aligned}
& \underbrace{\int_{\hat{\mathcal{C}}^{r}}\left[r_{o}-P_{o, t+1}\left(c_{o, t+1}\right)\right] d G\left(c_{o, t+1}\right)}_{\text {renew immediately }} \\
& +\underbrace{\int_{\hat{C}^{s}}\left[r_{o} Z\left(\frac{P_{o, t+1}\left(c_{o, t+1}\right)}{c_{o, t+1}}\right)-c_{o, t+1} \int_{0}^{\frac{P_{o, t+1}\left(c_{o, t+1}\right)}{c_{o, t+1}}} \epsilon d Z(\epsilon)\right] d G\left(c_{o, t+1}\right)}_{\text {search and sign non-renewable }} \\
& +\underbrace{\int_{\hat{C}^{s}}\left[r_{o}-P_{o, t+1}\left(c_{o, t+1}\right)\right]\left[1-Z\left(\frac{P_{o, t+1}\left(c_{o, t+1}\right)}{c_{o, t+1}}\right)\right] d G\left(c_{o, t+1}\right)}_{\text {search and then renew }} \\
& -\underbrace{\int_{\hat{\mathcal{C}} \int_{0} \int_{0, t+1}^{r_{o}}}^{c_{o, t}}\left(r_{o}-\epsilon c_{o, t+1}\right) d Z(\epsilon) d G\left(c_{o, t+1}\right)}_{\text {sign non-renewable }} .
\end{aligned}
$$

Differentiating the above expression with respect to $r_{o}$ yields $\int_{\hat{\mathcal{C}}}\left[1-Z\left(\frac{r_{o}}{c_{o, t+1}}\right)\right] d G\left(c_{o, t+1}\right)$, which is strictly positive so $B^{r e n}\left(r_{o} ; t\right)-B^{\text {non }}\left(r_{o} ; t\right)$ is strictly increasing in $r_{o} \geq \hat{r}_{o}$.

Finally, since $B^{r e n}\left(r_{o} ; t\right)-B^{\text {non }}\left(r_{o} ; t\right), B^{r e n}\left(r_{o} ; t\right)$ and $B^{\text {non }}\left(r_{o} ; t\right)$ are increasing for sufficiently large $r_{o}$, consumers of any generation would purchase renewables if their valuation is sufficiently large.

Proof of Lemma 2: For part (i.), by (4) we have the following demand for $c_{o} \in \underline{\mathcal{C}}_{o}$,

$$
D_{o}\left(P_{y}, P_{o}\left(c_{o}\right)\right)=\left(1-m_{y}\right)\left[1-H\left(\bar{r}_{o}\right)\right] .
$$

The insurance company takes $\bar{r}_{o}$ as given, so for costs in $\underline{\mathcal{C}}_{o}$, the demand is independent of the variations in $P_{o}\left(c_{o}\right)$.

Suppose $c_{o} \in \underline{\mathcal{C}}_{o}$ is the actual cost and the insurance company reports $c_{o}^{\prime} \in \underline{\mathcal{C}}_{o}$, then the incentive compatible $\left\{P_{o}\left(c_{o}\right)\right\}$ requires $P_{o}\left(c_{o}\right) \geq P_{o}\left(c_{o}^{\prime}\right)$. Now suppose $c_{o}^{\prime}$ is the actual cost and the insurance company reports $c_{o}$, then the incentive compatibility requires $P_{o}\left(c_{o}\right) \leq P_{o}\left(c_{o}^{\prime}\right)$. Therefore, we have $P_{o}\left(c_{o}\right)=P_{o}\left(c_{o}^{\prime}\right)$ for any $c_{o}, c_{o}^{\prime} \in \underline{\mathcal{C}}_{o}$.

Finally, to show that $\underline{\mathcal{C}}_{o}=\left\{c_{o} \mid P_{o}\left(c_{o}\right)<\bar{r}_{o}\right\}$ has strictly positive measure, first assume that $\underline{\mathcal{C}}_{o}$ is measure zero. This implies that for almost all $c_{o} \in[\underline{c}, \bar{c}], P_{o}\left(c_{o}\right) \geq \bar{r}_{o}$. By (2), $0=\frac{P_{y}-P_{y}^{N R}}{1-m_{y}}$, which is a contradiction when $P_{y}>P_{y}^{N R}$.

For part (ii.), if $\left\{P_{o}\left(c_{o}\right)\right\}$ is incentive compatible, then for any $c_{o} \in[\underline{c}, \bar{c}]$ and $\varepsilon>0$ such 
that $c_{o}+\varepsilon \in[\underline{c}, \bar{c}]$ we have

$$
\begin{gathered}
{\left[P_{o}\left(c_{o}\right)-c_{o}\right] D_{o}\left(P_{y}, P_{o}\left(c_{o}\right)\right) \geq\left[P_{o}\left(c_{o}+\varepsilon\right)-c_{o}\right] D_{o}\left(P_{y}, P_{o}\left(c_{o}+\varepsilon\right)\right),} \\
{\left[P_{o}\left(c_{o}+\varepsilon\right)-\left(c_{o}+\varepsilon\right)\right] D_{o}\left(P_{y}, P_{o}\left(c_{o}+\varepsilon\right)\right) \geq\left[P_{o}\left(c_{o}\right)-\left(c_{o}+\varepsilon\right)\right] D_{o}\left(P_{y}, P_{o}\left(c_{o}\right)\right) .}
\end{gathered}
$$

Summing the incentive constraints yields $D_{o}\left(P_{y}, P_{o}\left(c_{o}\right)\right) \geq D_{o}\left(P_{y}, P_{o}\left(c_{o}+\varepsilon\right)\right)$. Since $D_{o}$ is weakly decreasing in $P_{o}$, incentive compatible premiums have to be weakly increasing in cost.

Finally, the existence of a cutoff follows immediately from the fact that $P_{o}$ is weakly increasing in cost and $P_{o}\left(c_{o}\right) \geq P_{o}\left(c_{o}^{\prime}\right)$ for any $c_{o} \in \overline{\mathcal{C}}_{o}$ and $c_{o}^{\prime} \in \underline{\mathcal{C}}_{o}$.

Proof of Lemma 3: For part (i.), suppose $P_{o}\left(c_{o}\right)<P_{o}^{*}\left(c_{o}\right)$ for some $c_{o} \in\left(c_{o}^{\prime}, c_{o}^{\prime \prime}\right)$. Since $P_{o}\left(c_{o}\right)$ is strictly increasing and continuous, then there exists $\varepsilon>0$ such that $P_{o}\left(c_{o}\right)<$ $P_{o}\left(c_{o}+\varepsilon\right)<P_{o}^{*}\left(c_{o}\right)$. The hazard rate is non-decreasing, so $\left(P_{o}-c_{o}\right)\left(1-H\left(P_{o}\right)\right)$ is single peaked. This implies

$$
\left[P_{o}\left(c_{o}+\varepsilon\right)-c_{o}\right]\left[1-H\left(P_{o}\left(c_{o}+\varepsilon\right)\right)\right]>\left[P_{o}\left(c_{o}\right)-c_{o}\right]\left[1-H\left(P_{o}\left(c_{o}\right)\right)\right]
$$

which violates incentive compatibility at $c_{o}$. The argument also applies for $P_{o}\left(c_{o}\right)>P_{o}^{*}\left(c_{o}\right)$.

For part (ii.), it is trivial to show that $\bar{r}_{o}>\bar{P}_{o}$ from (2) when $P_{y}>P_{y}^{N R}$. To show that $P_{o}\left(c^{T}\right)>\bar{r}_{o}$, we only need to rule out $\bar{r}_{o}=P_{o}\left(c^{T}\right)$. If $\bar{r}_{o}=P_{o}\left(c^{T}\right)$, then by (8), we have $\bar{P}_{o}=\bar{r}_{o}$. By $(2)$, it implies that $0=\frac{P_{y}-P_{y}^{N R}}{1-m_{y}}$, which is a contradiction when $P_{y}>P_{y}^{N R}$.

Next, we will establish the fact that the frictionless premium is not incentive compatible for $\overline{\mathcal{C}}_{o}$. By $(2), \bar{r}_{o}>\bar{P}_{o}$. Suppose $P_{o}\left(c_{o}\right)=P_{o}^{*}\left(c_{o}\right)$ for all $c_{o} \in \overline{\mathcal{C}}_{o}$, then (8) implies

$$
L H S \equiv\left(\bar{P}_{o}-c^{T}\right)\left[1-H\left(\bar{r}_{o}\right)\right]=R H S \equiv\left(P_{o}^{*}\left(c^{T}\right)-c^{T}\right)\left[1-H\left(P_{o}^{*}\left(c^{T}\right)\right)\right] .
$$

Notice the following: $L H S<\left(\bar{P}_{o}-c^{T}\right)\left[1-H\left(\bar{P}_{o}\right)\right]$. Since $R H S$ is the optimal frictionless profit, it follows that $R H S>L H S$, and is only equal when $P_{y} \leq P_{y}^{N R}$ and with strict inequality when $P_{y}>P_{y}^{N R}$. Hence, it cannot be the case that $P_{o}\left(c_{o}\right)=P_{o}^{*}\left(c_{o}\right)$ for all $c_{o} \in \overline{\mathcal{C}}_{o}$.

Finally, we will show there is rigidity in $\overline{\mathcal{C}}_{o}$. Define $P_{o}^{+}\left(c^{T}\right) \equiv \lim _{c_{o} \rightarrow c^{T}} P_{o}\left(c_{o}\right)$ and $c^{M}=P_{o}^{*-1}\left(P_{o}^{+}\left(c^{T}\right)\right)$. Consider $c_{o} \in\left(c^{T}, \min \left\{c^{M}, \bar{c}\right\}\right)$, then $P_{o}^{+}\left(c^{T}\right)>P_{o}^{*}\left(c_{o}\right)$. By Lemma 2, $P_{o}$ is weakly increasing, so $P_{o}\left(c_{o}\right) \geq P_{o}^{+}\left(c^{T}\right)$ for any $c_{o} \in\left(c^{T}, \min \left\{c^{M}, \bar{c}\right\}\right)$. Suppose there exists $\hat{c}_{o} \in\left(c^{T}, \min \left\{c^{M}, \bar{c}\right\}\right)$ such that $P_{o}\left(\hat{c}_{o}\right)>P_{o}^{+}\left(c^{T}\right)$. This implies the following ordering: $P_{o}\left(\hat{c}_{o}\right)>P_{o}^{+}\left(c^{T}\right)>P_{o}^{*}\left(\hat{c}_{o}\right)$. However, $\left(P-\hat{c}_{o}\right)(1-H(P))$ is single peaked 
around $P_{o}^{*}\left(\hat{c}_{o}\right)$, so

$$
\left(P_{o}^{+}\left(c^{T}\right)-\hat{c}_{o}\right)\left(1-H\left(P_{o}^{+}\left(c^{T}\right)\right)\right)>\left(P_{o}\left(\hat{c}_{o}\right)-\hat{c}_{o}\right)\left(1-H\left(P_{o}\left(\hat{c}_{o}\right)\right)\right) .
$$

This violates incentive compatibility, so $P_{o}\left(c_{o}\right)$ is rigid for $c_{o} \in\left(c^{T}, \min \left\{c^{M}, \bar{c}\right\}\right)$.

Proof of Theorem 1: From Proposition 1 of Melumad and Shibano (1991), the proposed incentive compatible premium is globally incentive compatible. From Lemma 1 and Lemma 3 , the optimal incentive compatible premium has to take this form.

\section{E Solving the Model}

To solve the model, we use the theory presented in section 4 and formulate the profit maximization problem for insuring old consumers as follows:

$$
\begin{aligned}
\Pi_{o}^{*}=\max _{\bar{P}_{o}, \overline{\bar{P}}_{o}, c^{T}, c^{M}} & \int_{\underline{c}}^{c^{T}}\left(\bar{P}_{o}-c_{o}\right)\left[1-H\left(\bar{r}_{o}\right)\right] g\left(c_{o}\right) d c_{o} \\
& +\int_{c^{T}}^{c^{M}}\left(\overline{\bar{P}}_{o}-c_{o}\right)\left[1-H\left(\overline{\bar{P}}_{o}\right)\right] g\left(c_{o}\right) d c_{o} \\
& +\int_{c^{M}}^{\bar{c}}\left(P_{o}^{*}\left(c_{o}\right)-c_{o}\right)\left[1-H\left(P_{o}^{*}\left(c_{o}\right)\right)\right] g\left(c_{o}\right) d c_{o}
\end{aligned}
$$

subject to (9) and $\overline{\bar{P}}_{o}=P_{o}^{*}\left(c^{M}\right)$. Let $\lambda$ denote the Lagrange multiplier on (9). Given the distributional assumptions: $h\left(r_{o}\right)=\frac{1}{\gamma} \exp ^{-\frac{\left(r_{o}-\theta\right)}{\gamma}}$ and $g\left(c_{o}\right)=\frac{1}{\bar{c}-\underline{c}}$, from the first-order conditions, we can derive the following premiums:

$$
\begin{aligned}
& \bar{P}_{o}=\frac{\gamma}{\frac{\partial \bar{r}_{o}}{\partial \bar{P}_{o}}}+c^{T}-\frac{0.5\left(c^{T}-\underline{c}\right)^{2}}{\lambda(\bar{c}-\underline{c})+c^{T}-\underline{c}}, \\
& \overline{\bar{P}}_{o}=\gamma+c^{T}-\frac{0.5\left(c^{M}-c^{T}\right)^{2}}{\lambda(\bar{c}-\underline{c})-c^{M}+c^{T}} .
\end{aligned}
$$

The monopoly premium is $P_{o}^{*}\left(c_{o}\right)=\gamma+c_{o}$. Since $\overline{\bar{P}}_{o}=P_{o}^{*}\left(c^{M}\right)$, we have

$$
c^{M}=c^{T}+2 \lambda(\bar{c}-\underline{c}) .
$$

To solve for $\lambda$ and $c^{T}$, we need (9) and the first-order condition on $c^{T}$ :

$$
\frac{c^{T}-\underline{c}}{\bar{c}-\underline{c}}\left[\bar{P}_{o}-0.5\left(c^{T}+\underline{c}\right)\right] \frac{\partial \bar{r}_{o}}{\partial c^{T}}=\lambda\left[\gamma\left(e^{-\frac{\bar{P}_{o} \bar{r}_{o}}{\gamma}}-1\right)-\frac{\partial \bar{r}_{o}}{\partial c^{T}}\left(\bar{P}_{o}-c^{T}\right)\right] .
$$


To solve for the model equilibrium, we apply the following numerical algorithm:

1. Choose $P_{y}$ to maximize the firm's total profit (7).

2. Given the choice of $P_{y}$, select $c^{T}$ such that the FOC (16) holds under two cases:

(a) the upper cost threshold hits a corner, i.e. $c^{M}=\bar{c}$.

(b) the upper cost threshold is interior and calculated according to (15).

Compare the resulting profit from the old (6) for each case and select the lower cost threshold $c^{T}$ for which it is maximized.

3. Given $\left\{P_{y}, c^{T}, c^{M}\right\}$, find the value of $\lambda$ for which the IC constraint (9) holds.

4. Given $\left\{P_{y}, c^{T}, c^{M}, \lambda\right\}$, compute the upper rigid price $\overline{\bar{P}}_{o}$ using (14), and select the value of lower rigid price $\bar{P}_{o}$ for which the FOC (13) holds.

5. Given $\left\{P_{y}, c^{T}, c^{M}, \lambda, \bar{P}_{o}, \overline{\bar{P}}_{o}\right\}$, find the value of $\bar{r}_{o}$ that makes condition (2) hold with equality. Approximate partial derivatives $\left\{\frac{\partial \bar{r}_{o}}{\partial \bar{P}_{o}}, \frac{\partial \bar{r}_{o}}{\partial c^{T}}\right\}$ necessary to compute the FOCs.

The algorithm is executed backwards, effectively nesting a sequence of five optimization or root-finding problems.

\section{F Reputation Mechanism}

The analysis so far has implicitly assumed that cost is imposed on the insurers if they chose a premium that is not included in the promised set of renewal premia, say $P_{o} \in$ $\left(\bar{P}_{o}, \overline{\bar{P}}_{o}\right)$. Here, we formally model this cost through a reputation mechanism that disciplines the insurers. This self-enforcing mechanism is related to Alonso and Matouschek (2007) and Halac and Yared (2019), and its micro-foundations for price rigidity are similar to Nakamura and Steinsson (2011).

First, we find the equilibrium profit of an insurer without commitment power in a setting with a single generation. In this setting, the optimal premium set $\left\{P_{o}\left(c_{o}\right)\right\}$ of Theorem 1 is no longer an equilibrium, because after observing $\operatorname{cost} c_{o}$ the insurer sets the premium to

$$
P_{o}\left(c_{o}\right)=\max \left\{\bar{r}_{o}, P_{o}^{*}\left(c_{o}\right)\right\} \text {. }
$$

In fact, the insurer is unable to commit to any premium. This implies that the set of incentive compatible premium is an empty set. Therefore, the unique subgame perfect equilibrium 
of this game is characterized by none of the consumers signing and an equilibrium profit of $\underline{\Pi}=0$. We refer to this equilibrium as the discretionary equilibrium.

Next, we characterize the off-equilibrium path play of the insurer in our overlapping generations setting. For each generation $t$, the insurer proposes a renewal set or renewal premium $\left\{P_{o}\left(c_{o}\right)\right\}$ when the policyholders are young. We denote the insurer at this stage as $I_{y, t}$. Then, the insurer finalizes the renewal premium when the policyholders are old. We denote the insurer at this stage as $I_{o, t+1}$. To sustain the promised renewal premium set on path, we consider a trigger strategy: if $I_{o, t+1}$ deviates from the schedule set by $I_{y, t}$, then $I_{y, t+1}$ reverts to the discretionary equilibrium for all future generations. Formally, for any generation $t-1$ and realized cost $\tilde{c}_{o, t}$, the renewal premium set $\left\{P_{o, t}\left(c_{o, t}\right)\right\}$ satisfies the reneging constraint

$$
\frac{\delta}{1-\delta}(\Pi-\underline{\Pi}) \geq \hat{\Pi}_{o}\left(\tilde{c}_{o, t}\right)-\Pi_{o}\left(\tilde{c}_{o, t}\right)
$$

where $\Pi$ is given by $(7)$,

$$
\begin{gathered}
\hat{\Pi}_{o}\left(\tilde{c}_{o, t}\right)=\max _{P_{o}}\left(P_{o}-\tilde{c}_{o, t}\right)\left(1-m_{y}\right)\left[1-H\left(\max \left\{\bar{r}_{o, t-1}, P_{o}\right\}\right)\right], \\
\Pi_{o}\left(\tilde{c}_{o, t}\right)=\left(P_{o}\left(\tilde{c}_{o, t}\right)-\tilde{c}_{o, t}\right)\left(1-m_{y}\right)\left[1-H\left(\max \left\{\bar{r}_{o, t-1}, P_{o, t}\left(\tilde{c}_{o, t}\right)\right\}\right)\right],
\end{gathered}
$$

and $\bar{r}_{o, t-1}$ is determined by (2) for some $P_{y, t-1}$. Inequality (17) states that the one-time gain from taking advantage of the held-up policyholders $\hat{\Pi}_{o}-\Pi_{o}$ is less than the loss of future profits $\frac{\delta}{1-\delta}(\Pi-\underline{\Pi})$.

In essence, after observing a deviation, the consumers believe the insurer will set the renewal premiums at its discretion for all future generations. As a result, consumers do not sign with the insurer and it earns $\underline{\Pi}$. Similar to Nakamura and Steinsson (2011), the shift in consumer beliefs prevents the insurer from deviating and taking advantage of the held-up consumers. ${ }^{37}$ This gives us the following proposition.

Proposition 1 Let $\left\{P_{y},\left\{P_{o}\left(c_{o}\right)\right\}\right\}$ be the sequential optimal pricing rule that solves (6) and (7). Then, there exists a $\delta^{\prime}$ such that for any $\delta \geq \delta^{\prime},\left\{P_{y},\left\{P_{o}\left(c_{o}\right)\right\}\right\}$ is sustained as a stationary equilibrium.

Proposition 1 follows immediately from the fact that for any given sequential optimal pricing rule, there exists a $\delta^{\prime}$ such that (17) holds with equality and any $\delta$ larger than $\delta^{\prime}$ only relaxes the reneging constraint. This implies that as long as the interest rate $i_{t}$ is sufficiently small for all periods, then the reputation mechanism enforces the adherence of the optimal premium schedule in equilibrium.

\footnotetext{
${ }^{37}$ Alternatively, the off-path play can also be interpreted as a punishment the insurer imposes on itself for deviating in the past.
} 